\title{
Block copolymer based novel magnetic mixed matrix membranes- Magnetic modulation of water permeation by irreversible structural changes
}

\author{
Lakshmeesha Upadhyayaa,d,e, Mona Semsarilara, Damien Quemenera, Rodrigo Fernández-Pachecob, \\ Gema Martinez $^{\mathrm{c}, \mathrm{d}}$, Reyes Malladad, Isabel M. Coelhoso ${ }^{e}$, Carla A. M. Portugale ${ }^{*}$, João G. Crespo ${ }^{e}$ \\ anstitut Européen des Membranes, IEM, UMR 5635, Université de Montpellier, ENSCM, CNRS, Place Eugène Bataillon, 34095 \\ Montpellier Cedex 05, France \\ bLaboratorio de Microscopías Avanzadas (LMA), Instituto de Nanociencia de Aragón (INA), Edificio I+D, Campus Rio \\ Ebro.Universidad de Zaragoza, 50018, Zaragoza Spain \\ 'Networking Research Centre on Bioengineering, Biomaterials and Nanomedicine, CIBER-BBN, 28029 Madrid, Spain \\ dDepartment of Chemical and Environmental Engineering and Aragon Nanoscience Institute, Campus Río Ebro, C/ Mariano \\ Esquillor s/n ,50018 Zaragoza, Spain \\ e LAQV- REQUIMTE, Departamento de Química, Faculdade de Ciências e Tecnologia, Universidade Nova de Lisboa, Campus de \\ Caparica, 2829-516 Caparica, Portugal
}

\begin{abstract}
This contribution focuses on understanding the effect of magnetic field intensity on the performance of novel hydrophilic and hydrophobic mixed matrix membranes (MMMs). The hydrophilic MMMs were made up of polymeric nanoparticles (PNPs) that were synthesized through polymerization-induced selfassembly (PISA) and iron oxide nanoparticles prepared in presence of poly (methacrylic acid)- $b$ polyquaternized (2-dimethylamino)ethyl methacrylate. The hydrophobic MMMs were prepared by the addition of iron oxide nanoparticles with different surface properties to a linear poly (methacrylic acid)- $b$ poly (methylmethacrylate) diblock copolymer dissolved in tetrahydrofuran (THF). Three different types of hydrophilic membranes were prepared with polymeric nanoparticles of different morphologies (spherical, vermicular and vesicular). In case of the hydrophobic membranes, six different membranes containing different iron oxide core coated with different stabilizers such as poly (methacrylic acid), quaternized poly(2-dimethylamino)ethyl methacrylate and meso-2,3-dimercaptosuccinic acid were prepared. An external magnetic field with intensity values up to $1.15 \mathrm{~T}$ was used for the permeation studies and the results were compared with those obtained in the absence of magnetic field. The collected data indicate an increase in the water flux of up to $16 \%$ and $29 \%$ under the magnetic field for hydrophobic and hydrophilic membranes, respectively. The STEM analyses suggest that the magnetic nanoparticles move within the membrane structure during the application of the magnetic field. This displacement/rearrangement causes constant changes in the membrane structure (structure of the active layer) and consequently on the membrane permeability. These results suggest that the application of the magnetic field could be used as a pretreatment step to obtain high flux membranes.
\end{abstract}

Keywords: Polymerization-induced self-assembly, Magnetic nanoparticles, Non-solvent induced phase separation, Block copolymers, Membrane permeability, Magnetic field

\section{Introduction}

The fabrication of novel functional materials with complementary properties from organic and inorganic building blocks has attracted a major attention in the field of separation science[1-3]. Hybrid materials in 
the form of membranes have better chemical and pressure stability due to the presence of inorganic nanoparticles (INPs) and excellent flexibility due to the high structural versatility of polymer matrix or their building blocks[4]. The successful application of these nanocomposite membranes depends on the organic and inorganic components, as well as the chemical interaction between them. Previously various types of INPs such as $\mathrm{MgO}, \mathrm{TiO}_{2}, \mathrm{Fe}_{2} \mathrm{O}_{3}$, and $\mathrm{Fe}_{3} \mathrm{O}_{4}$ have been incorporated in the development of nanocomposite membranes[5-23].

Iron oxide nanoparticles are versatile nano-platforms which are mainly used in sensors, smart devices, catalysis, bioseparation, magnetically controlled drug delivery, magnetic resonance imaging (MRI), as well as in water treatment[24-30]. There are several references in the literature describing the preparation of mixed matrix membrane membranes using INPs to enhance their hydrophilicity, reduce the surface roughness and, thereby, improve the performance of membranes for liquid and gas separations[15,31-33].

However, only a few references in the literature explore the magnetic properties of the incorporated INPs for separation applications. Himstedt et al.[34] developed a magnetoresponsive nanofiltration membrane by grafting a magnetically responsive nanolayer consisting of hydrophilic poly(2-hydroxyethyl methacrylate) (PHEMA) chains, grown from the surface of a thin film nanofiltration membrane by surface-initiated atom transfer radical polymerization (SI-ATRP). Superparamagnetic materials were attached to chain ends, and an oscillating magnetic field was applied, producing the oscillation of the chains. Incorporation of NPs enhanced fouling resistance and reduced cake formation during filtration by disrupting the concentration polarization boundary layer. Later, Yang et al.[35] used the modified Gabriel synthesis procedure to attach superparamagnetic nanoparticles to the chain ends of PHEMA, and the membrane performance was studied using $\mathrm{CaCl}_{2}$ and $\mathrm{MgSO}_{4}$ filtration. It was found that salt rejection of the membrane, under an alternate magnetic field, increased compared to membrane filtration in the absence of an external magnetic field. This increase was greater for higher densities of attached INPs.

Santos et al.[36] used supported magnetic ionic liquid membranes for $\mathrm{CO}_{2}$ separation using PVDF as porous support. There was an increase in gas permeability for $\mathrm{CO}_{2}, \mathrm{~N}_{2}$, and air. This was related to the decrease of the viscosity of the ionic liquid, in the presence of an external magnetic field. Recently, Gebreyohannes et al.[23] used superparamagnetic ferric oxide NPs coated with polyethylene glycol dispersed in PVDF matrix. The INPs were used as an enzyme carrier, as well as, nanofillers in the membranes which were reversibly magnetizable due to the presence of the superparamagnetic iron oxide nanoparticles. These nanocomposite membranes were used in bioreactor showing a $75 \%$ reduction in membrane filtration resistance, due to reduced pore clogging resultant from the use of magnetic nanoparticles with immobilized enzyme.

In our previous work[37], we have demonstrated the possibility of making novel block copolymer based hydrophilic mixed matrix membranes made from polymeric nanoparticles of different morphologies (spheres, worms, and vesicles) using the polymerization induced self-assembly (PISA) technique and iron oxide nanoparticles with positive surface charge (iron oxide core coated with quaternized poly(2dimethylamino)ethyl methacrylate)). The primary purpose to add the INPs was to enhance the mechanical stability of the active layer made up of block copolymer via opposite electrostatic charges (PNPs with negative surface charge and INPs with positive surface charge). Later, we demonstrated[38] the fabrication of hydrophobic mixed matrix membranes from simple linear diblock copolymer (PMAA- $b$ PMMA) and iron oxide nanoparticles coated with different types of stabilizers $\left(\mathrm{PMMA}_{47}, \mathrm{PMAA}_{47}-b-\right.$ 
PQDMAEMA $_{50}$, and DMSA). The polymeric particles of linear block copolymer in casting solution were produced using iron oxide NPs dispersed in water followed by preparing the membranes via both tape casting and spin coating technique by non-solvent induced phase separation. The goal of the current work is to explore the performance of these hydrophilic and hydrophobic mixed matrix membranes under different magnetic field intensities. Analysis of the magnetic field effect on membrane performance was accomplished, based on the hydraulic permeability at $\mathrm{pH} 7.1$, and interpreted based on the influence of the magnetic field on permeate flux and on the relaxation behavior of the membrane after exposure to the magnetic field.

\section{Experimental}

\subsection{Materials}

Methacrylic acid (contain $250 \mathrm{ppm}$ of MEHQ as inhibitor, 99\%), methyl methacrylate (contain $\leq 30 \mathrm{ppm}$ MEHQ as inhibitor, 99\%), 4-cyano-4 (phenylcarbonothioylthio) pentanoic acid (>97\%), 4,4'-azobis(4cyanovaleric acid) (ACVA; 98\%), 2-dimethylaminoethyl methacrylate (contains 700-1000 ppm of monomethyl ether hydro-quinone as inhibitor, 98\%), methyl iodide, tetrahydrofuran (THF), iron(III) chloride hexahydrate (97\%, Reagent grade), iron(II) chloride tetrahydrate $(\geq 99 \%)$, ammonium hydroxide(28 \%), Triethylene glycol (99\%) and meso-2, 3-dimercaptosuccinic acid (98\%) were purchased from Sigma-Aldrich and were used as received. NMR solvents, $\mathrm{CD}_{3} \mathrm{OD}, \mathrm{CDCl}_{3}$, and $\mathrm{D}_{2} \mathrm{O}$, were purchased from Eurisotop, Saint Aubin, France.

\subsection{Membrane Fabrication and Characterization}

The hydrophilic mixed matrix membranes were prepared following the method described by Upadhyaya et al.[37]. The nanocomposite membranes were prepared from poly(methacrylic acid)- $b$-poly(methyl methacrylate) (PMAA- $b$-PMMA) of different morphologies such as spheres (PMAA $47-b-\mathrm{PMMA}_{185}$; Polydispersity Index, $\mathrm{D}=1.06$, Number Average Molecular weight, $M_{n}=19.5 \mathrm{~kg} / \mathrm{mol}$ ), worms $\left(\mathrm{PMAA}_{47^{-}}\right.$ $b$-PMMA $\left.267 ; \mathrm{Ð}=1.08, M_{n}=27.4 \mathrm{~kg} / \mathrm{mol}\right)$ and vesicles $\left(\mathrm{PMAA}_{47}-b-\mathrm{PMMA}_{356} ; \mathrm{Ð}=1.24, M_{n}=28.4 \mathrm{~kg} / \mathrm{mol}\right)$ synthesized via polymerization induced self-assembly (PISA) and iron oxide nanoparticles coated with quaternized poly(2-dimethylamino)ethyl methacrylate. The casting solutions were then spin coated on microporous nylon support.

The hydrophobic mixed matrix membranes were prepared following the method described by Upadhyaya et al.[38]. The membranes made by using a mixture of a linear diblock copolymer (poly(methacrylic acid)- $b$-poly(methylmethacrylate); $\mathrm{PMAA}_{47}-b-\mathrm{PMMA}_{69} ; \mathrm{Ð}=1.02 M_{n}=10.1 \mathrm{kgmol}^{-1}$ ) and magnetic iron oxide nanoparticles. The well-defined linear diblock copolymer of poly(methacrylic acid)- $b$-poly(methyl methacrylate) was synthesized using RAFT polymerization. The iron-oxide cores employed here were prepared using 3 different types of stabilizers $\left(\mathrm{PMAA}_{47}, \mathrm{PMAA}_{47}-b\right.$-PQDMAEMA 50 and meso-2,3dimercaptosuccinic acid). The membranes were prepared from casting solutions containing the diblock copolymer dissolved in THF, forming the PNPs by the addition of $0.35 \mathrm{~mL}$ of water containing dispersed iron oxide nanoparticles. Membranes were casted using either traditional tape casting or spin coating methods on microporous nylon support. Figure 1shows the schematic preparation of both hydrophilic and hydrophobic membranes using PNPs and INPs. 
Membrane top surface and cross section before and after filtration were observed by scanning electron microscopy (SEM). The SEM images were obtained using a Hitachi S4800 operating under $0.1 \mathrm{kV}$ to 30 $\mathrm{kV}$ working voltage. To prepare the SEM samples, the membranes on nylon film were frozen in liquid nitrogen for 10 min followed by sectioning.

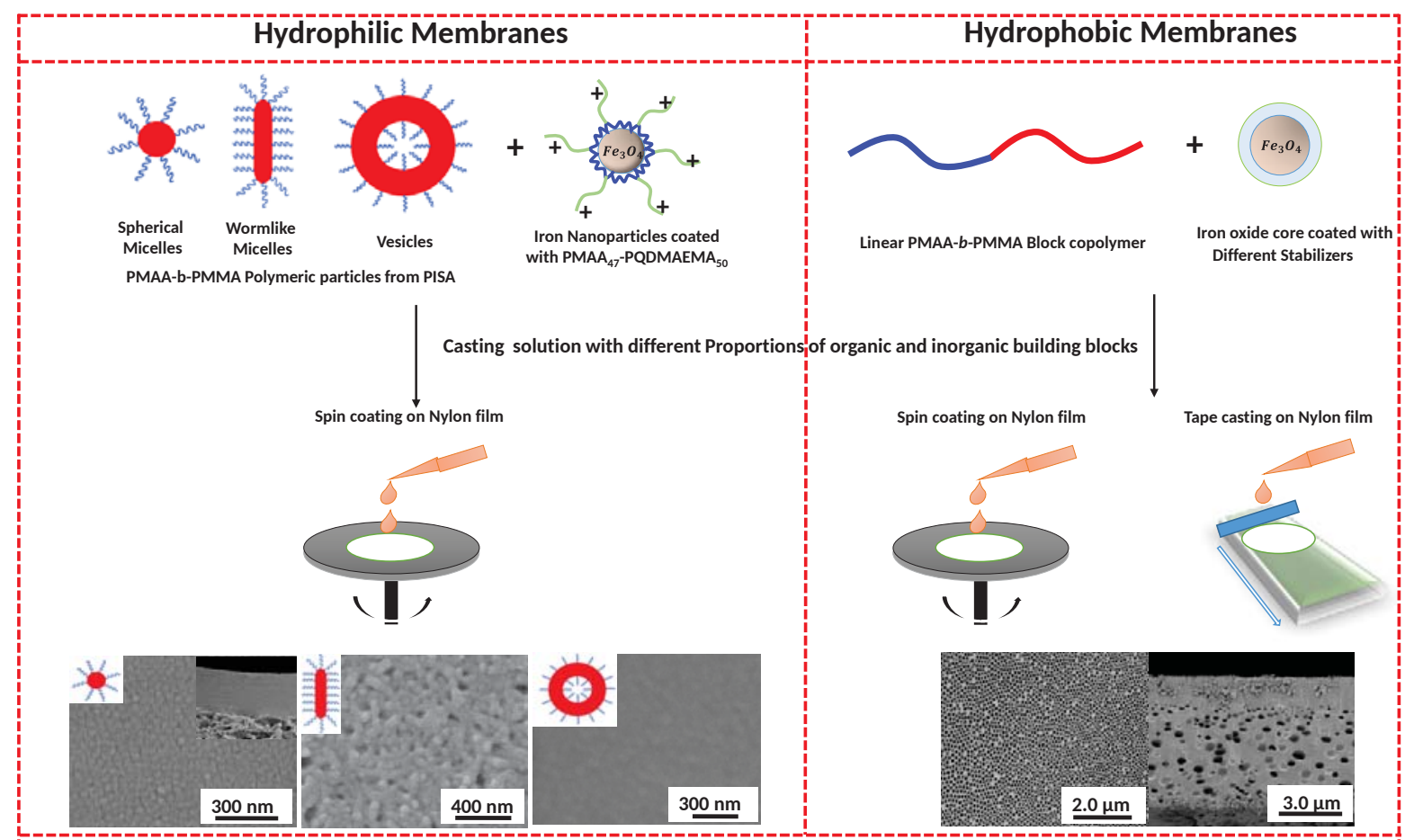

Fig. 1. Schematic representation of the fabrication of hydrophilic and hydrophobic membranes (Adapted from Ref 37 and 38)

To analyze the effect of magnetic field on membranes, atomic force microscopy (AFM) and scanning transmission electron microscopy (STEM) analysis were carried out. AFM images were obtained with a Pico SPM II provided by Molecular Imaging. The image was controlled by the PicoView 1.10 software. The experiments were all carried out in tapping mode. The types of tips used were PPS-FMR purchased from Nanosensors with a frequency resonance between 45 and $115 \mathrm{kHz}$ and a force constant between 0.5 and $9.5 \mathrm{~N} / \mathrm{m}$. Gwyddion 2.25 software was used to treat the images.

High Angle Annular Dark Field (HAADF) images were obtained with a Technai F30 (FEI) microscope, equipped with a Fischione HAADF detector at $300 \mathrm{keV}$ working voltage, in STEM mode. Also, in order to elucidate about the chemical composition of the materials, X-ray Energy Dispersive spectra (EDS) were obtained with an EDAX detector. In order to follow structural changes induced by the magnetic field at the same membrane spot, STEM analysis were not conducted with the membranes used in filtration experiments. Instead, the membranes were formed at a specific copper grid for STEM analysis. A diluted solution (10 times) of the original casting solution, which contains $1 \mathrm{~mL}$ of spherical particles in water with a concentration of $6.7 \mathrm{mg} / \mathrm{mL}$ and $2.1 \mathrm{~mL}$ of INPs in water, was cast on the top of a grid surface and then let to dry. Afterwards, 3 to 4 square sections on grids were marked and images were obtained without the presence of magnetic field and immediately upon exposure (to avoid analysis in the 
presence of magnetic relaxation) for $30 \mathrm{~min}$ to magnetic field conditions equal to those experienced by the membrane along the filtration process, i.e. perpendicularly to the surface with magnetic field strengths from $0.2 \mathrm{~T}$ to $1.15 \mathrm{~T}$. The TEM images acquired before and after magnetic field were obtained from the observation of the same square sections For magnetic relaxation studies, sample preparation was carried out as mentioned before. The grid was exposed to $1.15 \mathrm{~T}$ for $30 \mathrm{~min}$ and imaged immediately upon removal of the magnetic field (relaxation time of $0 \mathrm{~min}$ ) and at different time intervals along the relaxation time for comparative analysis.

\subsection{Filtration experiments under magnetic field}

The filtration tests were carried out in two different operation modes: dead-end and cross-flow filtration, at transmembrane pressures between 1 and 4 bar. All filtration experiments were repeated for three times. Error analysis was performed and the error bars were incorporated in the plots.

In experiments carried out in dead-end filtration mode, the membrane (diameter, $\mathrm{d}=2.5 \mathrm{~cm}$ and area of $4.9 \times 10^{-4} \mathrm{~m}^{2}$ ) was placed in a $10 \mathrm{~mL}$ dead end type filtration cell (Amicon 8010 stirred cell). Then, the filtration cell was connected to a water reservoir and compressed nitrogen. The flux and permeability were calculated based on Darcy's law [39] using Eq. (1) and, (2), where $V_{p}$ is the permeate volume collected, $\mathrm{t}$ is time, $\mathrm{S}$ is the membrane surface area, and $\Delta P$ is the pressure difference.

$\operatorname{Flux}\left(J_{V}\right)=V_{P} /(t * S)\left(\mathrm{L} \cdot \mathrm{h}^{-1} \cdot \mathrm{m}^{-2}\right)$

Permeability $\left(L_{P}\right)=J_{v} / \Delta P\left(\mathrm{~L} \cdot \mathrm{h}^{-1} \cdot \mathrm{m}^{-2} \cdot \mathrm{bar}^{-1}\right)$

The cross-flow mode filtration experiments were conducted in a homemade cross-flow cell comprising retentate and permeate inlet and outlet connections for feed/retentate recirculation and permeate sampling and recirculation to the retentate side (area of the membrane, $S=2.3 \mathrm{~cm} \times 1.2 \mathrm{~cm}$ ) (see Fig.2). The mass of the water permeating the membrane (permeate) was recorded by a balance connected to the SartoConnect software at regular time intervals. All dead-end and cross-flow filtration experiments were performed at room temperature (in a temperature-controlled room, $\mathrm{T}=22 \pm 1{ }^{\circ} \mathrm{C}$ ) with dust free ultra pure water, filtered through a 400-micron filter. Before the filtration experiments, the membranes were exposed to increasing and decreasing transmembrane pressure cycles up to 4 bar for structural stabilization, as well as to eliminate the possibility of structural compaction and effects on particle arrangement due to pressure along the filtration experiments, in all types of hydrophilic and hydrophobic prepared membranes.

Dead-end mode filtration experiments were conducted in the absence and presence of an external magnetic field oriented perpendicularly to the membrane surface. The permeation experiments (crossflow) were performed in the presence of a uniform magnetic field through the membrane thickness. In the initial studies, dead-end and cross-flow filtration experiments in the presence of magnetic field were carried out by placing a simple neodymium magnet at the bottom of the filtration cell, allowing for magnetic field intensities up to $0.15 \mathrm{~T}$ at the membrane top surface.

The experiments in the cross-flow cell were extended to higher magnetic field strengths (up to a maximum magnetic field of $1.15 \mathrm{~T}$, limited by the minimum pole distance required to fit the cross-flow cell). Filtration experiments at higher magnetic field intensities were possible by placing the cross-flow 
cell within the poles of a GMW Dipole Electromagnet (Model 3473-70, USA). Both, dead-end and crossflow filtrations were performed at lower magnetic field intensities, i.e. up to $0.15 \mathrm{~T}$ to compare the influence of magnetic field on the two filtration modes. Fig.2 shows the setup used for cross-flow filtration by placing the module between the poles of an electromagnet.

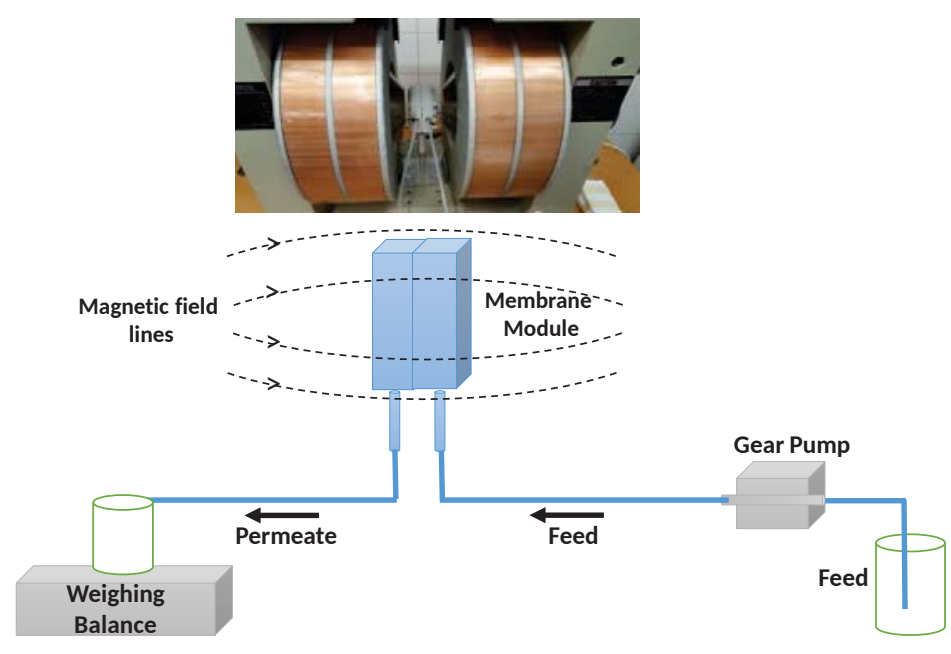

Fig. 2. Schematic representation of cross-flow filtration setup without retentate recycle.

\section{Results and Discussion}

\subsection{Performance of hydrophilic MMMs containing sphere-, worm-, and vesicle-like structured top layers}

At the early stage, filtration experiments were carried out at low magnetic field intensities (up to $0.15 \mathrm{~T}$ ) using the Amicon cell coupled to a neodymium magnet. The permeate fluxes obtained with hydrophilic membranes containing sphere, worm and vesicle-like structured top layers at variable transmembrane pressures from 1 to 4 bar are represented in Fig.3. For the membrane with spherical like structured top layer, the permeate flux without magnetic field was about $375.3 \mathrm{~L} \cdot \mathrm{h}^{-1} \cdot \mathrm{m}^{-2}$ at a transmembrane pressure of $4 \mathrm{bar}$. This value increased to $420.3 \mathrm{~L} \cdot \mathrm{h}^{-1} \cdot \mathrm{m}^{-2}$ at the same transmembrane pressure and a magnetic field strength of $0.15 \mathrm{~T}$, corresponding to about $12 \%$ increase in the permeate flux value. The membranes made from vesicles and worm-like micelles showed the same behavior, but the effect of magnetic field on the membrane hydraulic permeability was lower. The membranes with vesicle-like and worm-like structured top layers showed $9.5 \%$ and $2.3 \%$ increase in the permeate fluxes, respectively. The membranes with worm-like micellar structured top layer depicted the lowest increase in the flux, which was most probably due to their compact structure and the high entanglement of the vermicular structures.

The comparison between the permeate fluxes obtained by using the dead-end and the cross-flow filtration set-ups carried out by varying the magnetic field intensity from 0 to $0.15 \mathrm{~T}$ using neodymium magnets, 
and GPW dipole electromagnet system is shown as Supplementary Information (SI) in Tables S1, S2, and S3. The results show similar behavior for all transmembrane pressures and magnetic field intensities applied, irrespective of the operation mode used.
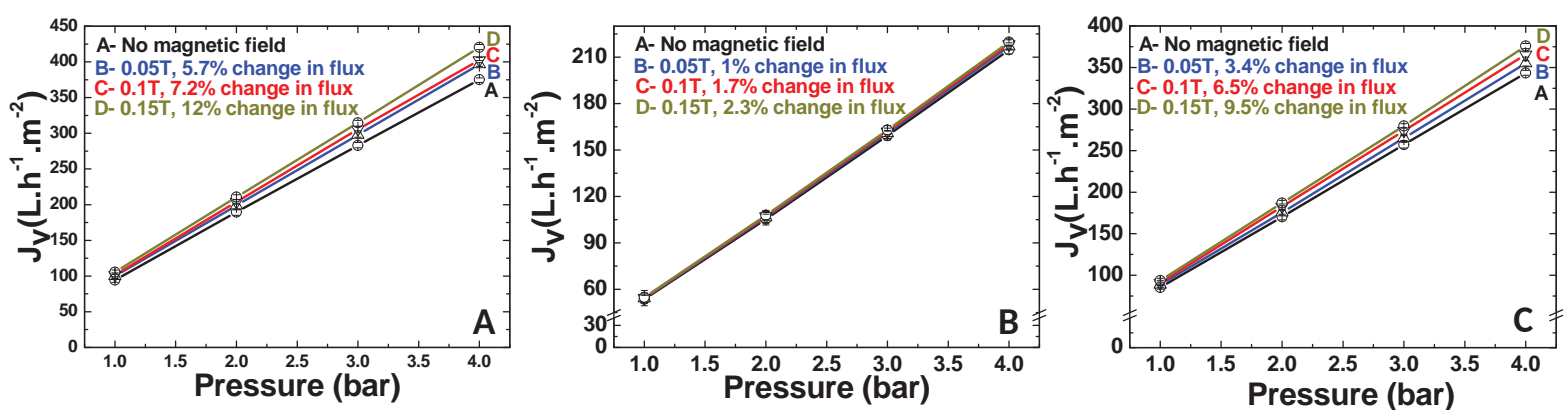

Fig. 3. Permeate flux values obtained for membranes with (A) spherical (B) vermicular (C) vesicular structured top layers, in dead-end mode, in the absence and presence of magnetic field at intensities up to $0.15 \mathrm{~T}$.

\subsection{Performance of hydrophilic MMMs under higher magnetic field intensity, cross-flow filtration}

The evolution of the permeate flux in the presence of magnetic field strength up to $0.4 \mathrm{~T}$ with a crossflow configuration is shown in Fig. S1. Similarly to that observed for filtrations carried out in dead-end mode, filtrations in cross-flow mode conducted in the presence of a magnetic field led to an increase of the permeate flux of $21.2 \%, 18.2 \%$ and $3.2 \%$, at $0.4 \mathrm{~T}$, for the membranes with sphere, vesicle, and worm-like structured top layers, respectively. Fig.4 illustrates the variation of the permeate water fluxes versus transmembrane pressure when exposed to higher magnetic field strengths of $0.8 \mathrm{~T}$ and $1.15 \mathrm{~T}$, at $298.15 \mathrm{~K}$. These results show that, when the magnetic field is increased to the maximum limit achievable in this set-up, i.e., $1.15 \mathrm{~T}$, the membranes with sphere-like structured top layers show a $29.4 \%$ increase in the permeate flux, whereas membranes with vesicular structure show an increase of $24.8 \%$.
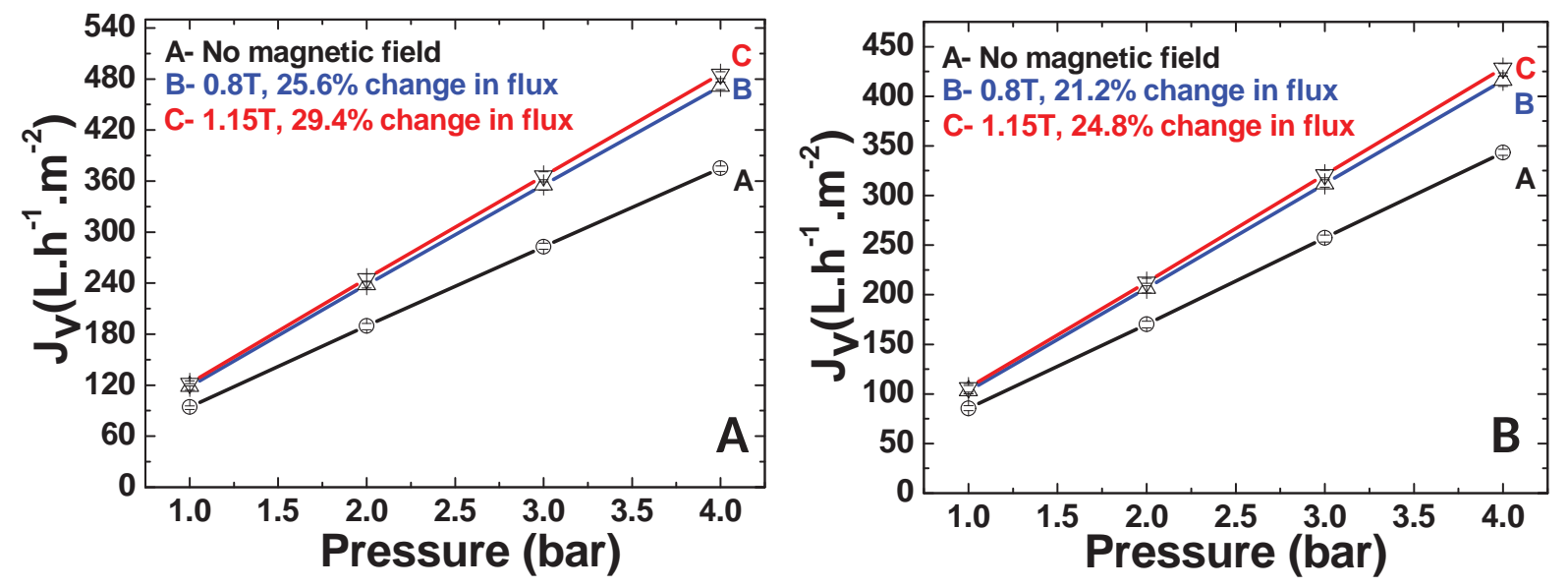

Fig. 4. Permeate flux profiles obtained for membranes with (A) sphere-like structured top layer (B) vesicle-like structured top layer based membranes, in cross-flow mode, in the absence and presence of magnetic field with intensities up to $1.15 \mathrm{~T}$. 
The increase of the hydraulic permeability of the three membrane types (for a magnetic field up to $0.4 \mathrm{~T}$ ) due to the magnetic field is shown in Fig.S2. Also, it can be seen that in all cases, the hydraulic permeability remained constant at increasing transmembrane pressures evidencing the excellent structural stability of the membranes during each experiment at constant magnetic field. The increase of hydraulic permeability observed is exclusively ascribed to the changes in the magnetic field intensity and/or time that the membranes are exposed to the magnetic field.

\subsection{Variations in the structural configuration of membranes under magnetic field}

The increase in permeate fluxes may be due to magnetic induced changes in the hydrophilicity of the membranes [7,40-42], local heating created by a magnetic field [43] or rearrangement of organic and inorganic building blocks of the membrane itself. Contact angle measurements of the membranes before and after filtration under magnetic field revealed that there were no changes in hydrophilicity of the membranes (contact angle $=46^{\circ}$ ). Long-term experiments were conducted to check possible magnetic induced local temperature changes at the membrane. These experiments were performed by exposing the membrane at the maximum magnetic field intensity $(1.15 \mathrm{~T})$ while immersed in a small volume of water $(5 \mathrm{~mL})$ for $50 \mathrm{~h}$. No change of the temperature in the water bath was noticed ( $296 \mathrm{~K})$ thus the assumption of local heating was reasonably eliminated. Therefore, the sole reason for the observed changes in the permeate flux values is the magnetically induced rearrangement of the INPs within the membrane structure, causing variations in the membrane top layer porosity and consequently increasing the permeate flux. To confirm this hypothesis, the membranes were analyzed using AFM before and after filtration in the absence of magnetic field $(0 \mathrm{~T})$ and in the presence of magnetic field intensities of $0.4 \mathrm{~T}$ and $1.15 \mathrm{~T}$. The AFM images obtained, shown in Fig.S3 and Fig.S4, do not evidence for the presence of structural changes occurring on the membrane top surface.

The structural changes induced by the magnetic field on the membrane top layer were evidenced by scanning transmission electron microscopy (STEM). A comparative analysis of STEM images obtained for the same membrane spot upon exposure to different magnetic field intensities revealed the presence of a magnetic induced INP clustering. INP clustering is denoted by the increase of bright regions (corresponding to the INPs) observed, whose dimension increases with the increase of the magnetic field intensity. Since these INPs are attached to PNPs, INP clustering is expected to be followed by rearrangements of PNPs which could be the reason for small compaction effect showed in Fig.S3B. These magnetic induced particle clustering effects seem to alter the porosity of the compact layer and, thereby, lead to an increase in the permeate flux.

The structural changes induced by the magnetic field on the membrane top layer were evidenced by scanning transmission electron microscopy (STEM). A comparative analysis of STEM images obtained for the same membrane spot upon exposure to different magnetic field intensities revealed the presence of a magnetic induced displacement of the INPs with consequent change of the uniform distribution of the INPs at the membrane surface (Fig. 5). Such effect is revealed in STEM images by the increase of the dimension of brighter regions as the magnetic field was increased. The chemical nature of the brighter regions was analysed by EDS (Fig.S5) and confirmed to correspond to the iron oxide nanoparticles (INPs). The EDS image clearly indicate the local increase in concentration of the iron oxide nanoparticles as the magnetic field across the membrane increased. Therefore, the enlargement of the brighter regions observed suggests that the magnetic field induced the formation of INP clustering, which is stronger as 
the magnetic field was increased from $0 \mathrm{~T}$ to $1.15 \mathrm{~T}$ (Fig. $5 \mathrm{~A}$ to Fig. $5 \mathrm{E}$ ). As reported in the literature [44-49], the superparamagnetic nanoparticles attain the configuration of superparamagnetic nanoparticle clusters (e.g. chains, rods and aggregates) during the application of the magnetic field. This is due to magnetic dipole-dipole attractions between particles under the applied magnetic field. Kralj and Makovec [46] and Fermigier et al.[44] expressed the maximum attraction of magnetic dipolar interaction relative to the dissociative thermal energy (kT) by a dimensionless dipole strength " $\lambda$ " (Eq.3), which is directly proportional to the diameter of INPs and to the strength of the applied magnetic field. Higher values of $\lambda$, promote the presence of lateral interactions between adjacent INP chains leading to the formation of larger INP structures, such as bundles and clusters[50-52].

$$
\frac{U_{\max }}{k T}=-\lambda=\left(\pi \mu_{0}\left(\frac{d}{2}\right)^{3} H^{2} \chi^{2}\right) / 9 k T
$$

$\mathrm{U}_{\max }$ is a maximum potential energy of interaction between two spheres (2 INPs) with identical magnetic moments, $\mathrm{k}$ is Boltzmann constant, $\mathrm{T}$ is temperature, $\mathrm{d}$ is diameter of the INPs, $\chi$ is magnetic susceptibility, $\mu_{\mathrm{o}}$ is magnetic permeability and $\mathrm{H}$ is magnetic field.

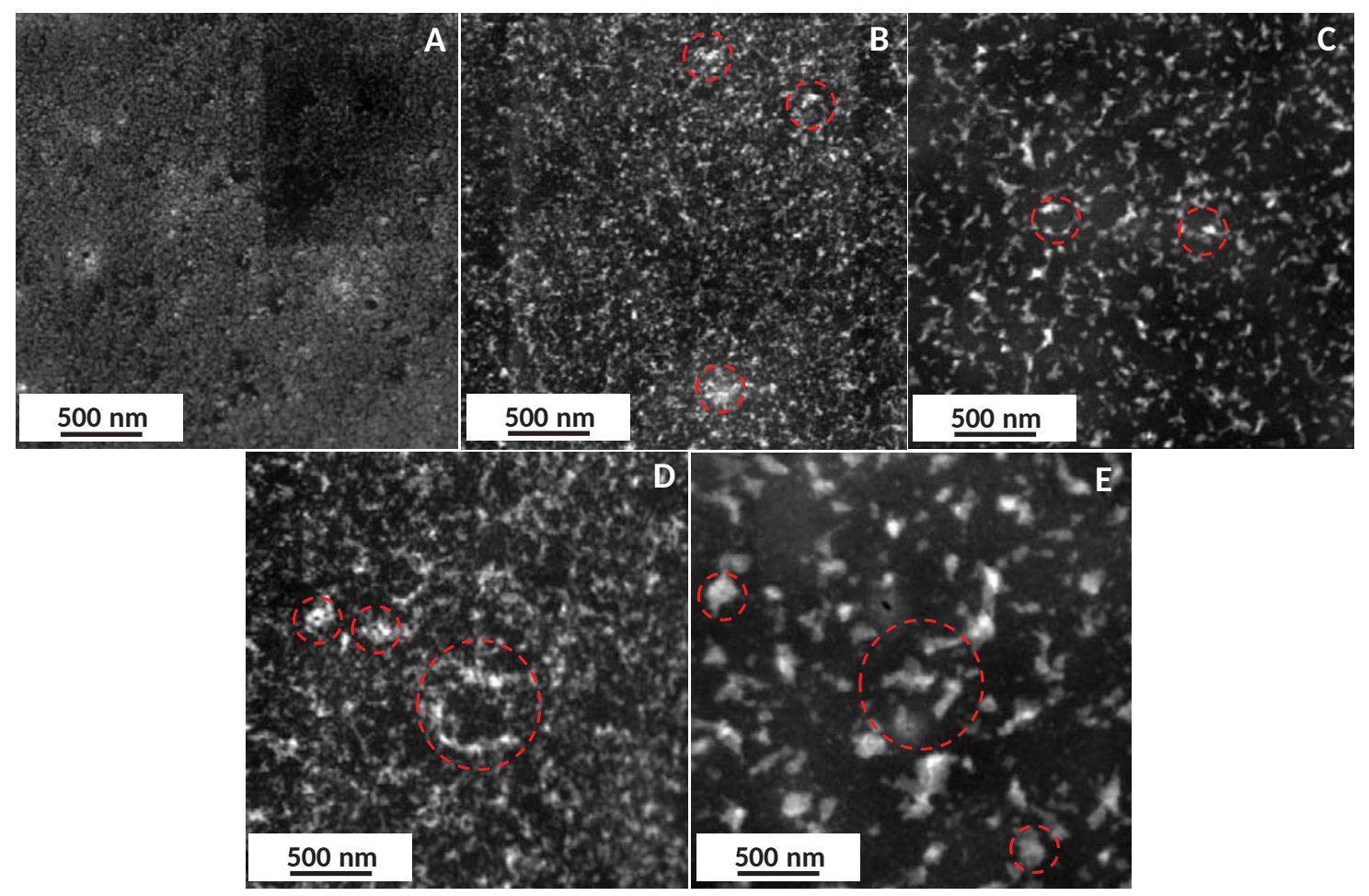

Fig. 5. STEM-HAADF images of a sphere-like structured top layer with INPs acquired immediately upon exposure to magnetic field intensities of (A) No field, (B) $0.2 \mathrm{~T}$, (C) $0.4 \mathrm{~T}$, (D) $0.6 \mathrm{~T}$ and (E) $1.15 \mathrm{~T}$. (Red zones showing some of the agglomeration spotted).

Beratoni et al.[48] studied the dependence of the clustering of superparamagnetic nanoparticles on the particle size. These authors showed that magnetic dipole-dipole forces predominate in interactions between larger particles favoring the formation of INP chains aligned according to the magnetic field direction. The formation of INP chains is less clear for smaller particles once dipole-dipole and van der 
Waal forces are comparable. Clustering of small particles are still visible in presence of a polymer[47], which attenuates the electrostatic interactions between particles. This theory was also supported by the work of Torre and coworkers[53] who used magnetic force microscopy (MFM) imaging to understand the process of clustering of small INPs under magnetic field and prove the theory of dipole-dipole interaction responsible for magnetic clustering.

In the present work, the INPs are attached and interspaced by polymer nanoparticles (PNPs). However, it is noteworthy that the INP aggregates shown in STEM images do not evidence for the presence of the INP magnetic alignment. The absence of chain structures may be either explained by the prevalence of electrostatic interactions despite the presence of PNPs or by the misalignment of the INPs immediately after the magnetic field removal. Furthermore, INP clustering is expected to be followed by rearrangements of PNPs. These magnetic induced particle clustering effects seem to alter the pore size distribution of the compact layer thereby leading to an increase in the permeate flux.

\subsection{Effect of the magnetic field on the permeate flux for hydrophilic MMMs}

The membranes with spherical and vesicle-like structured top layers were subjected to different magnetic field intensities keeping constant the operation time and the transmembrane pressure. Fig.6 shows the permeate fluxes obtained using membranes with sphere and vesicle-like structured top layers at increasing magnetic field intensity up to $1.15 \mathrm{~T}$ and at different transmembrane pressures (1,2 and 3 bar). Fig.6A shows the response of the membrane with a sphere-like structured top layer at various transmembrane pressures varying from 1 to 3 bar, whereas Fig. $6 \mathrm{~B}$ illustrates the same response at 3 bar of transmembrane pressure (a zoom in on Fig.6A). Figures 6C and D show the magnetic behavior of the permeate fluxes obtained using membranes with the vesicle-like structured top layer. The permeate fluxes obtained show that both membranes exhibited a change of magnetic dependence regime observed at ca. $0.4 \mathrm{~T}$. After an initial steep increase, seen at lower magnetic field intensities (up to $0.4 \mathrm{~T}$ ), the magnetic dependence of the permeate fluxes slows down, leading to a milder increase of permeate fluxes in the higher magnetic field range $(>0.4 \mathrm{~T})$. In the case of membranes with sphere-like structured top layers, the change in the permeate flux reached up to $21.2 \%$ and $29.4 \%$ at $0.4 \mathrm{~T}$ and $1.15 \mathrm{~T}$, respectively. The permeate flux profiles seem to tend to a constant value for magnetic field intensities higher than $1.15 \mathrm{~T}$, becoming independent from the magnetic field. However, this effect could not be confirmed in this work since the experimental set-up does not allow the development of experiments at higher field strength. The steeper and the milder permeate flux increase are clearly expressed by the slopes of the permeate flux data in the range of 0 to $0.4 \mathrm{~T}$ and $0.4 \mathrm{~T}$ to $1.15 \mathrm{~T}$ (Fig.6B and 6D). A comparative analysis of the slopes calculated in these two intervals shows a decrease of ca. $80 \%$ in the magnetic dependence of the permeate flux at higher magnetic fields, for both membrane types. Identical behavior was observed at lower transmembrane pressures ( 1 and 2 bar, see Fig.6A and 6C). The calculated slope values are presented in Table S4 (SI). 

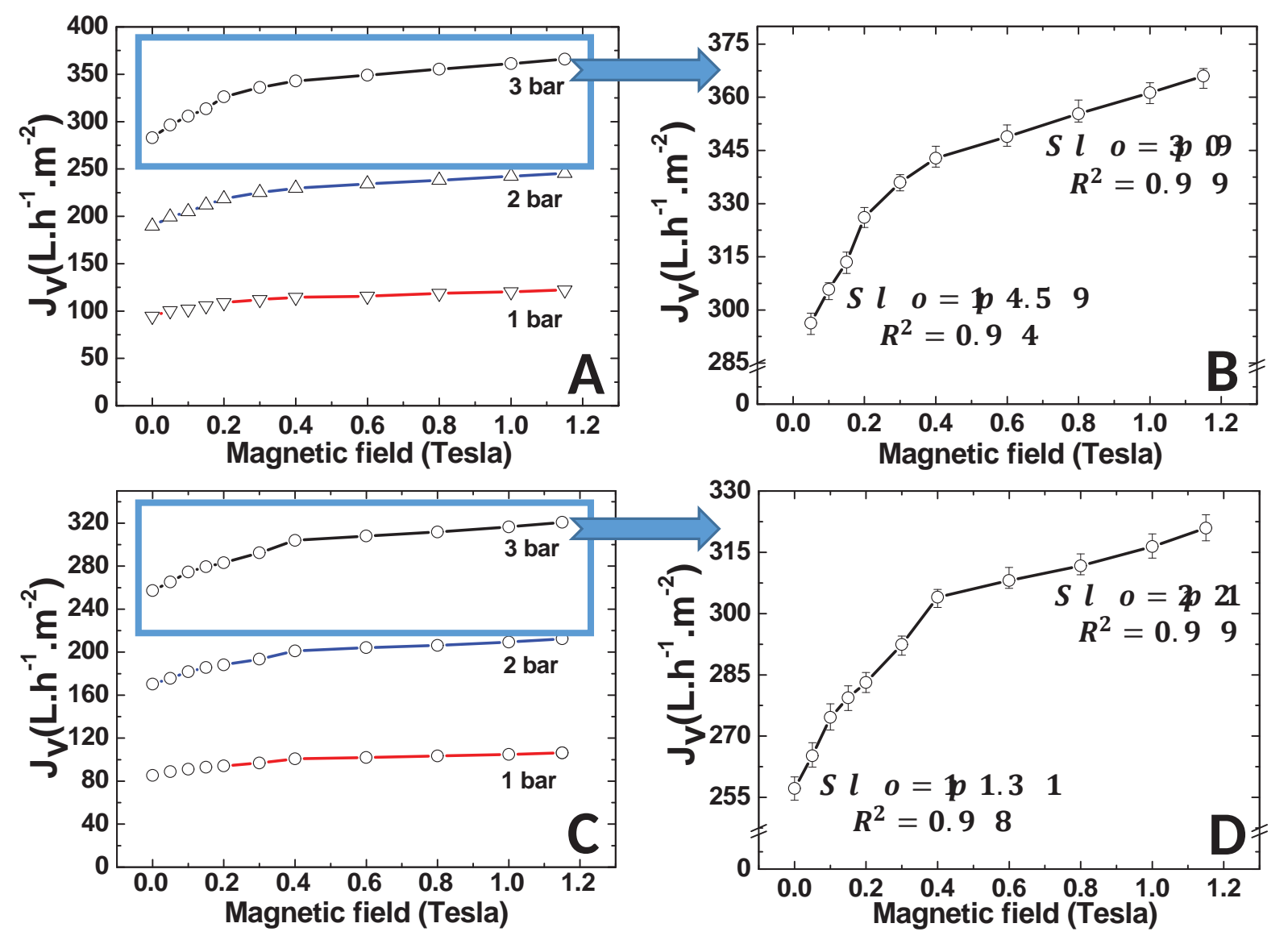

Fig. 6. Variation of the permeate flux versus magnetic field intensity at different transmembrane pressures for membranes with (A) sphere-like structured top layer and (C) vesicle-like structured top layers. The profiles obtained at transmembrane pressure of 3 bar are zoomed for membranes with (B) sphere-like structured top layer and (D) vesicle-like structured top layer.

\subsection{Magnetic relaxation studies of hydrophilic MMMs}

Magnetic relaxation experiments were carried out at a transmembrane pressure of 3 bar using membranes with a sphere and vesicle-like structured top layer to determine the ability of these membranes to return to their original performance after removal of the magnetic field. The results presented in Fig.7 show that after switching off the magnetic field, the permeate fluxes exhibit a fast decrease during the first $10 \mathrm{~h}$, with the recovery of ca. $24.5 \%$ and $39.4 \%$ of the original permeate fluxes (permeate flux value corresponding to the unmodified membrane at 3 bar of TMP) for the sphere and vesicle-like membranes, respectively. After $10 \mathrm{~h}$ of relaxation, the decline of permeate fluxes became slower and after $72 \mathrm{~h}$, the permeate fluxes reached constant values of $337 \mathrm{~L} \cdot \mathrm{h}^{-1} \cdot \mathrm{m}^{-2}$ for membranes with a sphere-like top layers and $285.3 \mathrm{~L} \cdot \mathrm{h}^{-1} \cdot \mathrm{m}^{-2}$ for membranes with a vesicle-like top layers. It is noteworthy that the final permeate fluxes after complete relaxation $\left(337 \mathrm{~L} \cdot \mathrm{h}^{-1} \cdot \mathrm{m}^{-2}\right.$ and $285.3 \mathrm{~L} \cdot \mathrm{h}^{-1} \cdot \mathrm{m}^{-2}$ for membranes with sphere and vesiclelike structured top layer, respectively) were higher than the original permeate fluxes $\left(282.9 \mathrm{~L} \cdot \mathrm{h}^{-1} \cdot \mathrm{m}^{-2}\right.$ and 257.2 L.h ${ }^{-1} \cdot \mathrm{m}^{-2}$ for membranes with sphere and vesicle-like structured top layer, respectively), i.e. those 
obtained before the exposure of the membranes to the magnetic field. These results suggest that the changes in membrane porosity induced by the magnetic field are not entirely recovered after removal of the magnetic field, leading to membranes with a different structural configuration and improved permeate fluxes. Also, it is important to highlight that despite the long relaxation time, the decrease of the permeate flux observed immediately after the removal of the magnetic field evidences that the membrane structural recovery takes place as soon as the magnetic field is switched off.
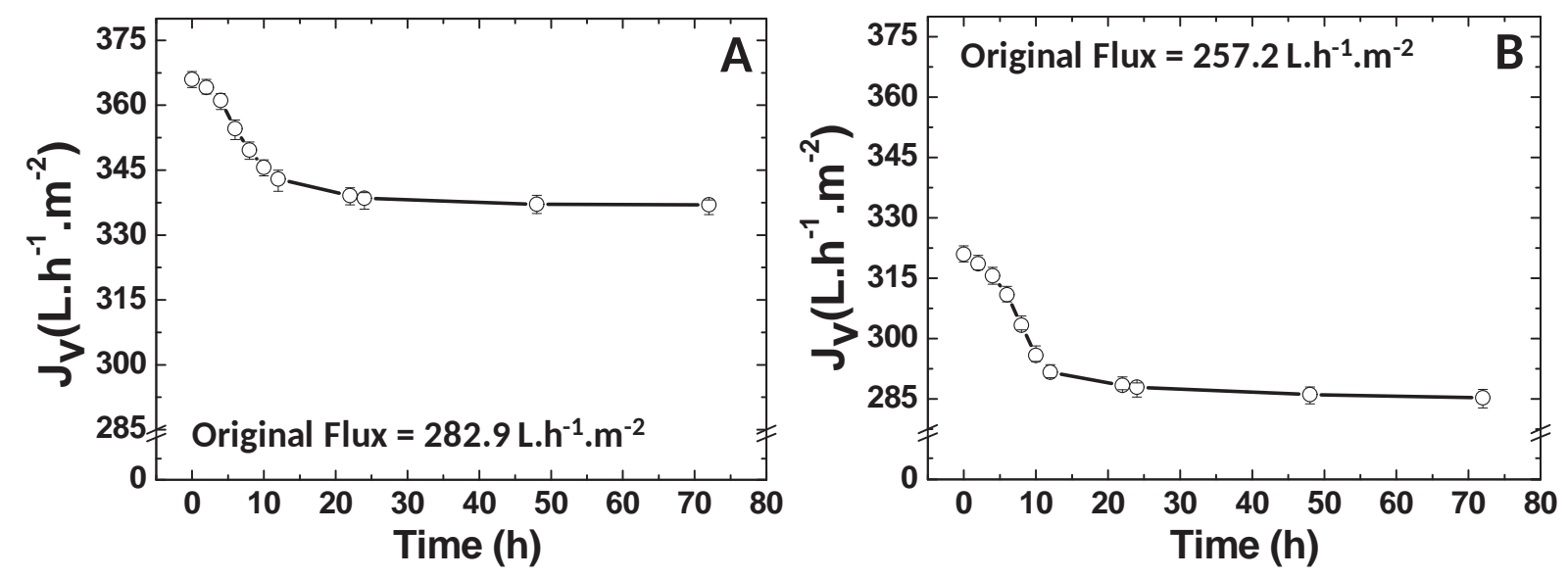

Fig. 7. Magnetic relaxation curve obtained for membranes with (A) sphere-like structured top layer and (B) vesiclelike structured top layer carried out at a transmembrane pressure of 3 bar after removal of magnetic field intensity of $1.15 \mathrm{~T}$.

The changes observed along the magnetic relaxation were also followed by STEM-HAADF analysis which provided images of the structural evolution of the sphere like structured top layered surfaces along the relaxation time which are shown in Fig. $8 \mathrm{~A}$ to E. The STEM-HAADF images showed the occurrence of significant structural changes along the first $10 \mathrm{~h}$ of relaxation, expressed by the surface recoverage with the INPs particles, much possibly as a consequence of the partial desintegration of the particle aggregates (previously formed in the presence of magnetic field). Additional structural changes from $20 \mathrm{~h}$ to $50 \mathrm{~h}$ of relaxation time are less notorious and absent for relaxation times higher than $50 \mathrm{~h}$, suggesting the attainance of a structural stabilization. A comparative analysis of STEM-HAADF images obtained for the membranes before exposure to the magnetic field (Fig. 5A) and upon a relaxation time (Fig. 8 E) shows that the initial structure of the membrane top layer is not totally recovered, evidencing that magnetic induced structural changes are partially irreversible. The structural behaviour exhibited by the membrane top layer along the relaxation time perfectly agrees with the recovery profile of the permeate fluxes observed along this period. These results confirm that the decrease of the permeate flux along the magnetic relaxation is associated to progressive redistribution of the membrane surface with the particles. As referred above, the most significant structural surface recovery occurs along the first $10 \mathrm{~h}$ of relaxation, where the decline of the permeate flux is more accentuated. The less significant permeate flux changes after this period follow the lower structural rearrangments observed at later stages of the magnetic relaxation. 

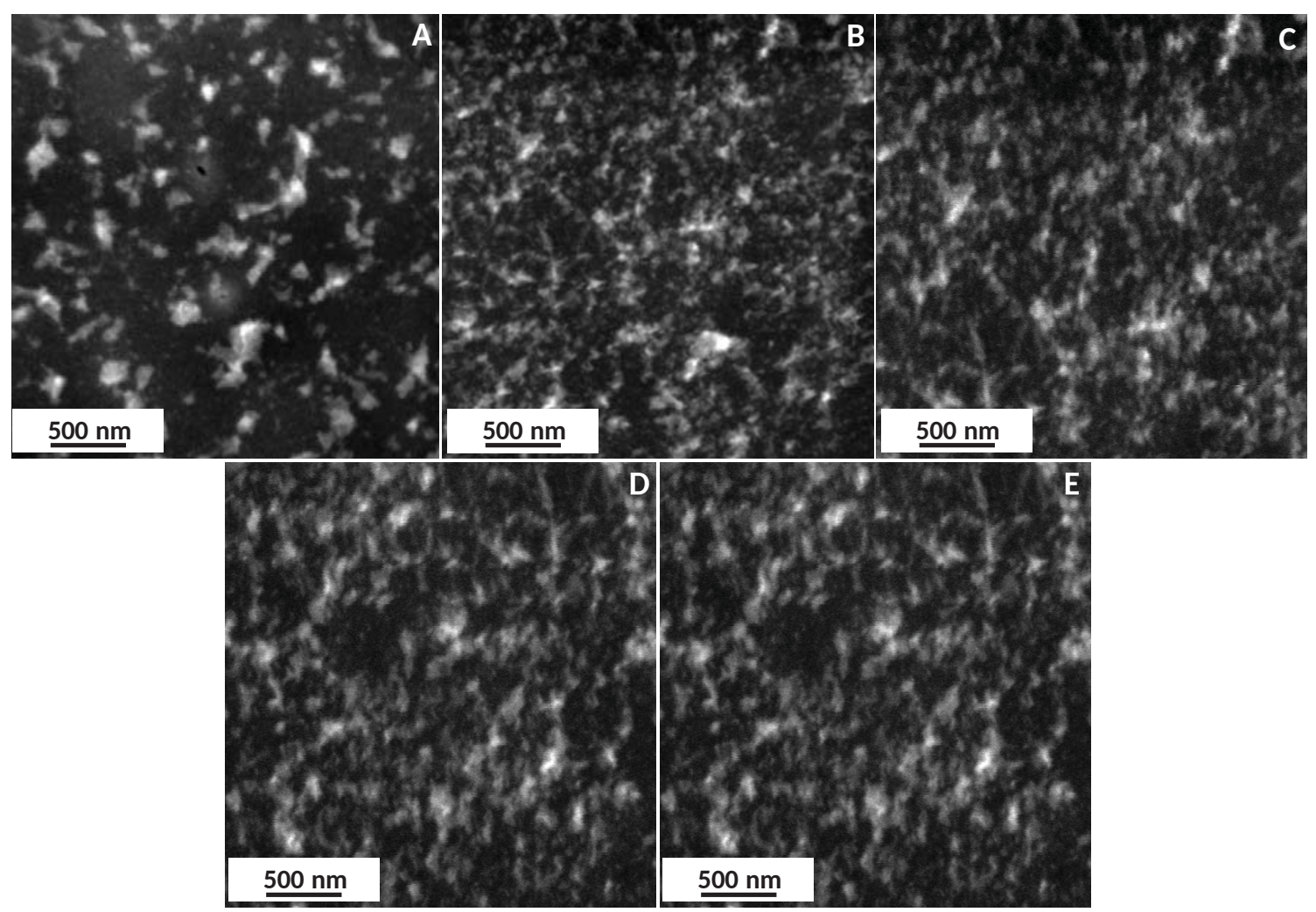

Fig. 8. STEM-HAADF images of a sphere-like structured top layer with INPs after a magnetic relaxation time of (A) $0 \mathrm{~h}$, (B) $10 \mathrm{~h}$, (C) $20 \mathrm{~h}$, (D) $50 \mathrm{~h}$ and (E) $70 \mathrm{~h}$.

\subsection{Performance of hydrophobic MMMs under magnetic field}

In our previous work [38] we have demonstrated the preparation, characterization, and filtration under magnetic field for the hydrophobic mixed matrix membranes prepared by non-solvent induced phase separation (NIPS) technique. Table 1 shows the percentage change in flux under magnetic field for membranes made through tape casting and spin coating procedures. From the STEM images (Fig.S6 in SI), magnetic induced rearrangements of INPs can be observed in a similar fashion as seen in the hydrophilic membranes. The resultant aggregation of the INPs translates into changes in the porosity during the application of the magnetic field, and therefore into a change in the overall permeate flux value. The percentage increase in permeate fluxes of hydrophobic membranes is detailed in Table 1. The increase in flux is doubled for the membranes with DMSA INPs compared to the membranes with PMAA $_{47}$ coated INPs. This could be related with higher magnetization value of DMSA-coated INPs compared to others forcing them to aggregate more hence changing more accentuatedly the overall porosity. However, it was not possible to obtain higher permeate flux changes because in this case the INPs are dispersed in the dense polymer matrix which restricts the movement of the INPs compared that in the nanoporous hydrophilic membranes prepared from individual PNPs. This is also further confirmed when comparing the same type of INPs (i.e. PMAA $_{47}-b$-PQDMAEMA ${ }_{50}$ ) embedded in the polymeric matrix (hydrophobic membranes) and at the membrane surface (hydrophilic membranes). The presence of 
INPs in the nanoporous hydrophilic membranes results in an increase of $29.4 \%$ versus $9.4 \%$ in the hydrophobic membranes.

Table 1. The performance of hydrophobic MMMs under magnetic field prepared through NIPS technique.

\begin{tabular}{|c|c|c|c|c|}
\hline $\begin{array}{c}\text { Membrane } \\
\text { type }\end{array}$ & $\begin{array}{c}\text { Type of stabilizer used for INPs } \\
\text { coating }\end{array}$ & $\begin{array}{c}\text { Flux at } 0 \mathrm{~T} \\
\left(\mathrm{~L} \cdot \mathrm{h}^{-1} \cdot \mathrm{m}^{-2}\right)\end{array}$ & $\begin{array}{c}\text { Flux at } 1.15 \mathrm{~T} \\
\left(\mathrm{~L} \cdot \mathrm{h}^{-1} \cdot \mathrm{m}^{-2}\right)\end{array}$ & $\begin{array}{c}\text { Flux change } \\
(\%)\end{array}$ \\
\hline \multirow{3}{*}{ Tape casting } & PMAA $_{47}$ & 99.7 & 108.8 & 8.3 \\
\cline { 2 - 5 } & $\mathrm{PMAA}_{47}-b$-PQDMAEMA & 130.9 & 151.1 & 9.4 \\
\cline { 2 - 5 } & DMSA $_{50}$ & 104.0 & 124.0 & 16.1 \\
\hline \multirow{3}{*}{ Spin coating } & PMAA $_{47}$ & 205.9 & 228.3 & 9.8 \\
\cline { 2 - 5 } & $\mathrm{PMAA}_{47}-b-\mathrm{PQDMAEMA}_{50}$ & 166.3 & 186.5 & 10.8 \\
\cline { 2 - 5 } & DMSA & 155.5 & 186.9 & 16.8 \\
\hline
\end{tabular}

\subsection{Effect of magnetic field on the permeate flux and relaxation studies of hydrophobic MMMs prepared by tape casting}

The percentage increase in permeate fluxes versus magnetic field intensity showed the same trend as previously observed with the hydrophilic membranes prepared with particles prepared through PISA technique. The behavior of the tape casted membranes containing PMAA $47, \mathrm{PMAA}_{47}-b-\mathrm{PQDMAEMA}_{50}$, and DMSA-coated INPs are shown in Fig.9. The membranes showed an initial steep increase in permeate flux value as the magnetic field reaches the $0.2 \mathrm{~T}$ followed by a milder increase in flux confirming the two regimes of permeate flux increase. When a magnetic field is applied, the INP structure tends to rearrange, changing the porosity of the membrane top layer. As the magnetic field strength was increased to a higher value, the movement of INPs particles will be restricted at later stages by the density of the polymer matrix retarding/limiting the increase of permeate flux. The steeper and the milder permeate flux increase are clearly expressed by the slopes of the curve in the 0 to $0.2 \mathrm{~T}$ and $0.2 \mathrm{~T}$ to $1.15 \mathrm{~T}$ intervals.
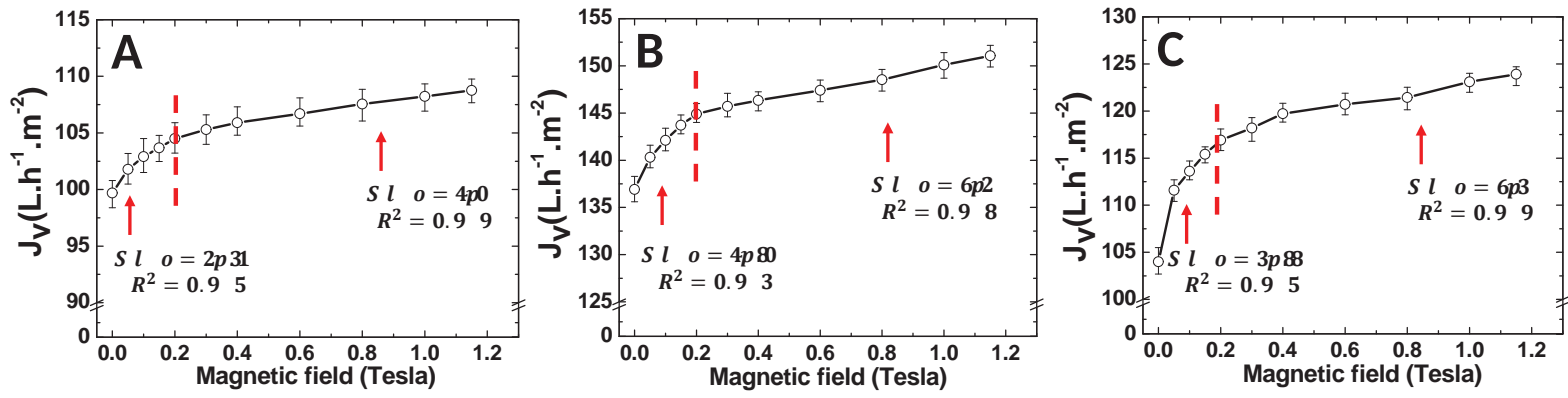

Fig. 9. Variation of the permeate flux versus magnetic field for tape cast membranes containing (A) $\mathrm{PMAA}_{47}(\mathrm{~B})$ $\mathrm{PMAA}_{47}-b$-PQDMAEMA ${ }_{50}(\mathrm{C})$ DMSA-coated iron oxide nanoparticles at transmembrane pressure of 4 bar.

To find out the ability of hydrophobic membranes to recover their original flux, magnetic relaxation experiments were carried out at a transmembrane pressure of 4 bar. The results obtained presented in Fig.10 showed to be similar to those obtained with the hydrophilic membranes where a fast decrease of permeate flux was observed (up to $10 \mathrm{~h}$ ) after removal of the magnetic field. The membranes containing 
PMAA $_{47}$ and PMAA $_{47}-b$-PQDMAEMA 50 coated INPs exhibited a recovery (in comparison with flux value of unmodified membranes) of ca. $29.6 \%$ and $23.2 \%$ after $10 \mathrm{~h}$ whereas membranes containing DMSA-coated nanoparticles displayed a recovery of $4 \%$ during the same time interval. After $10 \mathrm{~h}$ of experiment, the decline in the permeate flux became slower and reached a stationary zone, with constant values of $105.6 \mathrm{~L} \cdot \mathrm{h}^{-1} \cdot \mathrm{m}^{-2}, 147.8 \mathrm{~L} \cdot \mathrm{h}^{-1} \cdot \mathrm{m}^{-2}$ and $123.0 \mathrm{~L} \cdot \mathrm{h}^{-1} \cdot \mathrm{m}^{-2}$ for membranes with $\mathrm{PMAA}_{47}, \mathrm{PMAA}_{47}-b$ PQDMAEMA $_{50}$ and DMSA-coated INPs, respectively.
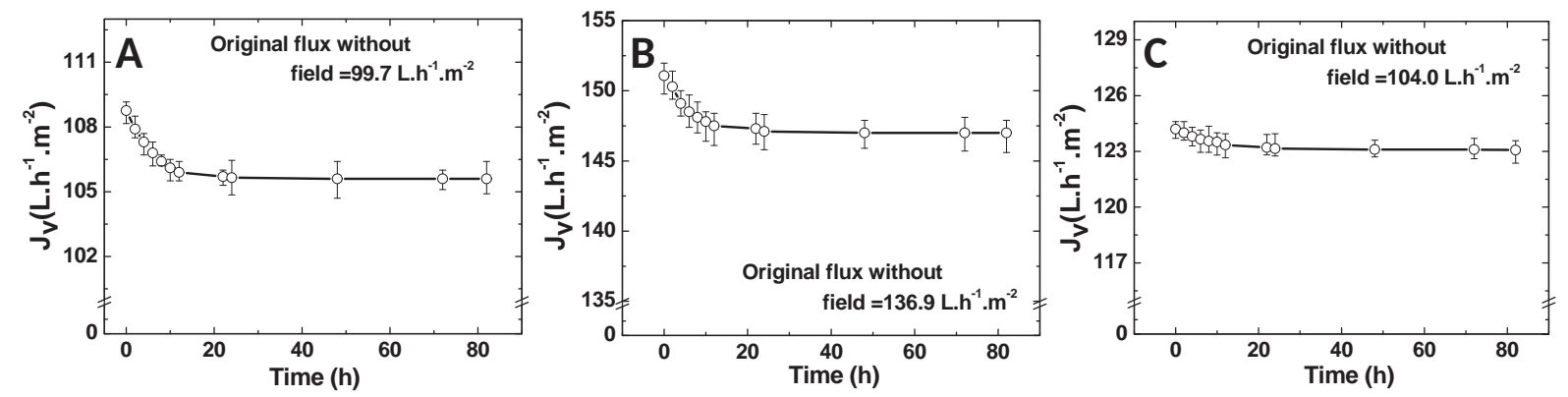

Fig. 10. Magnetic relaxation curve obtained for membranes containing (A) $\mathrm{PMAA}_{47}$ (B) $\mathrm{PMAA}_{47}-b-\mathrm{PQDMAEMA}_{50}$ (C) DMSA-coated iron oxide nanoparticles at 4 bar of transmembrane pressure with a magnetic field intensity of $1.15 \mathrm{~T}$.

The permeate fluxes of membranes with DMSA-coated INPs stabilize after a shorter time upon removal of the magnetic field, exhibiting a decrease of only one unit, which results in a larger deviation from the permeate flux value obtained before the magnetic field (i.e. the original permeate flux) (Fig.10C). The reason for this minute change in the permeate flux after removal of the magnetic field is probably due to the higher saturation magnetization of the DMSA-coated nanoparticles $(65 \mathrm{emu} / \mathrm{g})$ compared to the other INPs (around 10-12 emu/g) used in this work. When the magnetic field is applied, the magnetic nanoparticles move within the mixed matrix membrane and tend to aggregate due to magnetic attraction, thus porosity of the membrane increases. When the magnetic field is removed, the iron particles become completely nonmagnetic, that restricts further movement, freezing the created pores and hampering further recovery of the permeate flux value.

\section{Conclusions}

This work shows the effect of magnetic field on the performance of novel block copolymer based hydrophilic and hydrophobic mixed matrix membranes under magnetic field intensities varying from $0 \mathrm{~T}$ to $1.15 \mathrm{~T}$. An increase of about $24 \%$ to $29 \%$ in the permeate flux has been observed in hydrophilic membranes with vesicular and spherical structured top layers, whereas membranes with worm-like structured top layers did not show a significant response to the magnetic field. The limited responsive capacity of membranes with worm-like structured top layers may be explained by the presence of a compact top layer structure and a higher entanglement of the PNPs. The impact of magnetic field on the performance of hydrophobic membranes was smaller, with the permeate fluxes increasing from $8 \%$ to $16 \%$ in the presence of a magnetic field intensity of $1.15 \mathrm{~T}$. The microscopic sample analysis performed for both hydrophobic and hydrophilic membranes revealed that the increase of permeate fluxes are due to changes in the porosity of membrane top layer caused by magnetically induced INPs clustering effects. The permeate flux profiles at increasing magnetic field intensities revealed the presence of distinct 
permeate flux regimes. The initial region was characterized by a steep change in the permeate flux followed by a region at higher magnetic field intensities, where permeate flux changes were lower. The transition between these two regimes was found to occur at $0.4 \mathrm{~T}$ for hydrophilic membranes and $0.2 \mathrm{~T}$ for hydrophobic membranes.

The magnetic relaxation studies of both sets of membranes revealed that, once the permeate fluxes increase with the magnetic field, the original flux cannot be totally restored after removal of the magnetic field due to the permanent structural changes in the membrane. The hydrophobic membrane containing DMSA-coated INPs showed a higher sensitivity to the magnetic field than the other hydrophobic membranes studied while exhibiting quicker and smaller relaxation of the permeate fluxes. This faster relaxation may be related to the higher saturation magnetization value of the superparamagnetic INPs.

Application of the magnetic field to these membranes can act as a preliminary processing condition leading to a flux increase due to changes induced in the porosity of the compact top layer. The addition of INPs also fulfills the requirements of increasing the mechanical strength of the top layer, to withstand higher pressure or flow rates for separation processes. These membranes demonstrated some capacity to respond reversibly to the magnetic field, which may allow for the magnetic modulation of the membrane performance, i.e. solute permeability and fouling effects. These aspects will be analyzed and discussed in forthcoming papers.

\section{Acknowledgments}

The Doctorate of L.UPADHYAYA has been completed at the Institut Européen des Membranes and carried out in three universities: Université de Montpellier (France), Universidad de Zaragoza (Spain) and Universidade Nova de Lisboa (Portugal), and financed by a scholarship of the European Commission Education, Audiovisual and Culture Executive Agency (EACEA), under the program: Erasmus Mundus Doctorate in Membrane Engineering - EUDIME (FPA N 2011- 0014, Edition III, http:/eudime.unical.it). This work was also supported by the Associated Laboratory for Sustainable Chemistry- Clean Processes and Technologies-LAQV which is financed by national funds from FCT/MCTES (UID/QUI/50006/2013) and co-financed by the ERDF under the PT2020 Partnership Agreement (POCI-01-0145-FEDER$\underline{007265})$.

\section{References}

[1] Y. Gu, R.M. Dorin, U. Wiesner, Asymmetric Organic-Inorganic Hybrid Membrane Formation via Block Copolymer-Nanoparticle Co-Assembly, Nano Lett. 13 (2013) 5323-5328. doi:10.1021/n1402829p.

[2] P. Madhavan, P.-Y. Hong, R. Sougrat, S.P. Nunes, Silver-Enhanced Block Copolymer Membranes with Biocidal Activity, ACS Appl. Mater. Interfaces. 6 (2014) 18497-18501. doi:10.1021/am505594c.

[3] L. Upadhyaya, M. Semsarilar, R. Fernández-Pacheco, G. Martinez, R. Mallada, A. Deratani, D. Quemener, Porous membranes from acid decorated block copolymer nano-objects via RAFT alcoholic dispersion polymerization, Polym. Chem. 7 (2016) 1899-1906. doi:10.1039/C5PY01888A.

[4] M. Ulbricht, Advanced functional polymer membranes, Polymer (Guildf). 47 (2006) 2217-2262. doi:10.1016/j.polymer.2006.01.084.

[5] V. Vatanpour, S. Siavash, A. Reza, E. Salehi, S. Zinadini, H. Ahmadi, TiO 2 embedded mixed matrix PES nanocomposite membranes: In fl uence of different sizes and types of nanoparticles on antifouling and 
performance, DES. 292 (2012) 19-29. doi:10.1016/j.desal.2012.02.006.

[6] P. Daraei, S. Siavash, N. Ghaemi, M. Ali, B. Astinchap, Separation an d Purification Techn ology Fouling resistant mixed matrix polyethersulfone membranes blended with magnetic nanoparticles: Study of magnetic field induced casting, Sep. Purif. Technol. 109 (2013) 111-121. doi:10.1016/j.seppur.2013.02.035.

[7] A. Rybak, Z.J. Grzywna, P. Sysel, Mixed matrix membranes composed of various polymer matrices and magnetic powder for air separation, Sep. Purif. Technol. 118 (2013) 424-431. doi:10.1016/j.seppur.2013.07.026.

[8] M. Sairam, M.B. Patil, R.S. Veerapur, S.A. Patil, T.M. Aminabhavi, Novel dense poly ( vinyl alcohol )TiO 2 mixed matrix membranes for pervaporation separation of water - isopropanol mixtures at $30 \circ \mathrm{C}$, J. Memb. Sci. 281 (2006) 95-102. doi:10.1016/j.memsci.2006.03.022.

[9] L.F. Greenlee, Oxidation behavior of zero-valent iron nanoparticles in mixed matrix water purification membranes, Environ. Sci. Water Res. Technol. 1 (2015) 146-152. doi:10.1039/C4EW00068D.

[10] F. Moghadam, M.R. Omidkhah, M.Z. Pedram, F. Dorosti, The effect of TiO 2 nanoparticles on gas transport properties of Matrimid5218-based mixed matrix membranes, Sep. Purif. Technol. 77 (2011) 128-136. doi:10.1016/j.seppur.2010.11.032.

[11] A. Rybak, G. Dudek, M. Krasowska, A. Strzelewicz, Z.J. Grzywna, Magnetic Mixed Matrix Membranes Consisting of PPO Matrix and Magnetic Filler in Gas Separation, Separartion Sci. Technol. 49 (2014) 17291735. doi:10.1080/01496395.2014.906465.

[12] M. Nemati, S.M. Hosseini, Fabrication and electrochemical property modification of mixed matrix heterogeneous cation exchange membranes filled with Fe $3 \mathrm{O} 4$ / PAA core-shell nanoparticles, Ionics (Kiel). (2015). doi:10.1007/s11581-015-1603-z.

[13] P. Safaei, A. Marjani, M. Salimi, Mixed Matrix Membranes Prepared from High Impact Polystyrene with Dispersed TiO 2 Nanoparticles for Gas Separation, J. Nanostructure. 6 (2016) 74-79. doi:10.7508/jns.2016.01.012.

[14] J. Alam, L.A. Dass, M. Ghasemi, M. Alhoshan, Synthesis and optimization of PES-Fe ${ }_{3} \mathrm{O}_{4}$ mixed matrix nanocomposite membrane: Application studies in water purification, Polym. Compos. 34 (2013) 1870-1877. doi:10.1002/pc.22593.

[15] P. Daraei, S. Siavash, N. Ghaemi, E. Salehi, M. Ali, R. Moradian, B. Astinchap, Novel polyethersulfone nanocomposite membrane prepared by PANI / Fe 3 O 4 nanoparticles with enhanced performance for $\mathrm{Cu}$ ( II ) removal from water, J. Memb. Sci. 415-416 (2012) 250-259. doi:10.1016/j.memsci.2012.05.007.

[16] Y.H. Teow, A.L. Ahmad, J.K. Lim, B.S. Ooi, Preparation and characterization of PVDF / TiO 2 mixed matrix membrane via in situ colloidal precipitation method, DES. 295 (2012) 61-69. doi:10.1016/j.desal.2012.03.019.

[17] Y.H. Teow, B.S. Ooi, A.L. Ahmad, J.K. Lim, Mixed-Matrix Membrane for Humic Acid Removal: Influence of Different Types of TiO 2 on Membrane Morphology and Performance, Int. J. Chem. Eng. Appl. 3 (2012) 374-379. doi:10.7763/IJCEA.2012.V3.222.

[18] S.M. Momeni, M. Pakizeh, Preparation , Characterization and gas permeation study of PSf / MgO nanocomposite membrane, Brazillian J. Chem. Eng. 30 (2013) 589-597.

[19] F. Mohd Nor, R. Othaman, Effects of MgO particle loading on gas permeation properties of epoxidized natural rubber (ENR) / polyvinyl chloride (PVC) membrane, Sains Malaysiana. 44 (2015) 875-881.

[20] E. Mahmoudi, L. Yong, M.M. Ba-abbad, A.W. Mohammad, Novel nanohybrid polysulfone membrane embedded with silver nanoparticles on graphene oxide nanoplates, Chem. Eng. J. 277 (2015) 1-10. 
doi:10.1016/j.cej.2015.04.107.

[21] M. Tong, S. Yuan, H. Long, M. Zheng, L. Wang, J. Chen, Reduction of nitrobenzene in groundwater by iron nanoparticles immobilized in PEG / nylon membrane, J. Contam. Hydrol. 122 (2011) 16-25. doi:10.1016/j.jconhyd.2010.10.003.

[22] A.S. Al-hobaib, K.M. Al-sheetan, L. El Mir, Materials Science in Semiconductor Processing Effect of iron oxide nanoparticles on the performance of polyamide membrane for ground water puri fi cation, Mater. Sci. Semicond. Process. 42 (2016) 107-110. doi:10.1016/j.mssp.2015.08.004.

[23] A.Y. Gebreyohannes, M.R. Bilad, T. Verbiest, C.M. Courtin, E. Dornez, L. Giorno, E. Curcio, I.F.J. Vankelecom, Nanoscale tuning of enzyme localization for enhanced reactor performance in a novel magnetic-responsive biocatalytic membrane reactor, J. Memb. Sci. 487 (2015) 209-220. doi:10.1016/j.memsci.2015.03.069.

[24] L. Yang, Z. Cao, H.K. Sajja, H. Mao, L. Wang, H. Geng, H. Xu, T. Jiang, W.C. Wood, S. Nie, Y.A. Wang, Development of Receptor Targeted Magnetic Iron Oxide Nanoparticles for Efficient Drug Delivery and Tumor Imaging., J. Biomed. Nanotechnol. 4 (2008) 439-449. doi:10.1166/jbn.2008.007.

[25] N. Lee, T. Hyeon, Designed synthesis of uniformly sized iron oxide nanoparticles for efficient magnetic resonance imaging contrast agents., Chem. Soc. Rev. 41 (2012) 2575-89. doi:10.1039/c1cs15248c.

[26] S. Laurent, D. Forge, M. Port, A. Roch, C. Robic, L. Vander Elst, R.N. Muller, Magnetic Iron Oxide Nanoparticles: Synthesis, Stabilization, Vectorization, Physicochemical Characterizations, and Biological Applications, Chem. Rev. 108 (2008) 2064-2110. doi:10.1021/cr068445e.

[27] M. Cao, Z. Li, J. Wang, W. Ge, T. Yue, R. Li, V.L. Colvin, W.W. Yu, Food related applications of magnetic iron oxide nanoparticles: Enzyme immobilization, protein purification, and food analysis, Trends Food Sci. Technol. 27 (2012) 47-56. doi:10.1016/j.tifs.2012.04.003.

[28] W. Wu, Z. Wu, T. Yu, C. Jiang, W.-S. Kim, Recent progress on magnetic iron oxide nanoparticles: synthesis, surface functional strategies and biomedical applications, Sci. Technol. Adv. Mater. 16 (2015) 23501. doi:10.1088/1468-6996/16/2/023501.

[29] W. Wu, Q. He, C. Jiang, Magnetic iron oxide nanoparticles: Synthesis and surface functionalization strategies, Nanoscale Res. Lett. 3 (2008) 397-415. doi:10.1007/s11671-008-9174-9.

[30] H. Kim, H. Hong, Y. Lee, H. Shin, J. Yang, Degradation of trichloroethylene by zero-valent iron immobilized in cationic exchange membrane, DES. 223 (2008) 212-220. doi:10.1016/j.desal.2007.03.015.

[31] P. Jian, H. Yahui, W. Yang, L. Linlin, Preparation of polysulfone - Fe 3 O 4 composite ultrafiltration membrane and its behavior in magnetic field, J. Memb. Sci. 284 (2006) 9-16. doi:10.1016/j.memsci.2006.07.052.

[32] L. Chunqing, S. Kulprathipanja, A.M.W. Hillock, S. Husain, W.J. Koros, Recent Progress in Mixed-Matrix Membranes, in: N.L. Norman, F. Anthony, W.. Winston Ho, T. Matsuura (Eds.), Adv. Membr. Technol. Appl., John Wiley \& Sons, Inc., 2008: pp. 790-819.

[33] G. Dong, V. Chen, Challenges and opportunities for mixed-matrix membranes for gas separation, J. Mater. Chem. B. 1 (2013) 4610-4630. doi:10.1039/c3ta00927k.

[34] H.H. Himstedt, Q. Yang, L.P. Dasi, X. Qian, S.R. Wickramasinghe, M. Ulbricht, Magnetically Activated Micromixers for Separation Membranes, Langmuir. 27 (2011) 5574-5581. doi:10.1021/la200223g.

[35] Q. Yang, H.H. Himstedt, M. Ulbricht, X. Qian, S.R. Wickramasinghe, Designing magnetic field responsive nanofiltration membranes, J. Memb. Sci. 430 (2013) 70-78. doi:10.1016/j.memsci.2012.11.068. 
[36] E. Santos, J. Albo, C.I. Daniel, C.A.M. Portugal, J.G. Crespo, A. Irabien, Permeability modulation of Supported Magnetic Ionic Liquid Membranes (SMILMs) by an external magnetic field, J. Memb. Sci. 430 (2013) 56-61. doi:10.1016/j.memsci.2012.12.009.

[37] L. Upadhyaya, M. Semsarilar, S. Nehache, D. Cot, R. Fernández-Pacheco, G. Martinez, R. Mallada, A. Deratani, D. Quemener, Nanostructured Mixed Matrix Membranes from Supramolecular Assembly of Block Copolymer Nanoparticles and Iron Oxide Nanoparticles, Macromolecules. 49 (2016) 7908-7916. doi:10.1021/acs.macromol.6b01738.

[38] L. Upadhyaya, M. Semsarilar, R. Fernández-Pacheco, G. Martinez, R. Mallada, I.M. Coelhoso, C.A.M. Portugal, J.G. Crespo, A. Deratani, D. Quemener, Nano-structured magneto-responsive membranes from block copolymers and iron oxide nanoparticles, Polym. Chem. 47 (2017) 2217-2262. doi:10.1039/C6PY01870J.

[39] R.W. Baker, Membrane Technology and Applications, John Wiley \& Sons, Ltd, Chichester, UK, 2012. doi:10.1002/9781118359686.

[40] R.D. Noble, Perspectives on mixed matrix membranes, J. Memb. Sci. 378 (2011) 393-397. doi:10.1016/j.memsci.2011.05.031.

[41] C.M. Zimmerman, A. Singh, W.J. Koros, Tailoring mixed matrix composite membranes for gas separations, J. Memb. Sci. 137 (1997) 145-154. doi:doi:10.1016/S0376-7388(97)00194-4.

[42] M.A. Aroon, A.F. Ismail, Performance studies of mixed matrix membranes for gas separation: A review, Sep. Purif. Technol. 75 (2010) 229-242. doi:10.1016/j.seppur.2010.08.023.

[43] Z. Kovziridze, J.G. Heinrich, R. Goerke, G. Mamniashvili, Z. Chachkhiani, N. Mitskevich, G. Donadze, Production of superparagnetic nanospheres for hyperthermic therapy of surface (skin) cancer diseases, IOP Conf. Ser. Mater. Sci. Eng. 18 (2011) 1-4. doi:10.1088/1757-899X/18/19/192018.

[44] M. Fermigier, A.P. Gast, Structure evolution in a paramagnetic latex suspension, J. Colloid Interface Sci. 154 (1992) 522-539. doi:10.1016/0021-9797(92)90165-I.

[45] F.E. Osterloh, H. Hiramatsu, R.K. Dumas, K. Liu, Fe $3 \mathrm{O}$ 4-LiMo 3Se 3 nanoparticle clusters as superparamagnetic nanocompasses, Langmuir. 21 (2005) 9709-9713. doi:10.1021/1a051498r.

[46] S. Kralj, D. Makovec, Magnetic Assembly of Superparamagnetic Iron Oxide Nanoparticle Clusters into Nanochains and Nanobundles, ACS Nano. 9 (2015) 9700-9707. doi:10.1021/acsnano.5b02328.

[47] J. Richardi, L. Motte, M.P. Pileni, Mesoscopic organizations of magnetic nanocrystal: The influence of short-range interactions, Curr. Opin. Colloid Interface Sci. 9 (2004) 185-191. doi:10.1016/j.cocis.2004.05.027.

[48] G. Bertoni, B. Torre, A. Falqui, D. Fragouli, A. Athanassiou, R. Cingolani, Nanochains formation of superparamagnetic nanoparticles, J. Phys. Chem. C. 115 (2011) 7249-7254. doi:10.1021/jp111235n.

[49] D. Eberbeck, F. Wiekhorst, U. Steinhoff, L. Trahms, Aggregation behaviour of magnetic nanoparticle suspensions investigated by magnetorelaxometry, J. Phys. Condens. Matter. 18 (2006) S2829-S2846. doi:10.1088/0953-8984/18/38/S20.

[50] Furst, Gast, Dynamics and lateral interactions of dipolar chains, Phys. Rev. E. Stat. Phys. Plasmas. Fluids. Relat. Interdiscip. Topics. 62 (2000) 6916-25. http://www.ncbi.nlm.nih.gov/pubmed/11102046 (accessed November 6, 2017).

[51] J.M. Laskar, J. Philip, B. Raj, Experimental evidence for reversible zippering of chains in magnetic nanofluids under external magnetic fields, Phys. Rev. E. $80 \quad$ (2009) 41401. doi:10.1103/PhysRevE.80.041401. 
[52] Q. Zhang, M. Janner, L. He, M. Wang, Y. Hu, Y. Lu, Y. Yin, Photonic Labyrinths: Two-Dimensional Dynamic Magnetic Assembly and in Situ Solidification, Nano Lett. 13 (2013) 1770-1775. doi:10.1021/n1400351k.

[53] B. Torre, G. Bertoni, D. Fragouli, A. Falqui, M. Salerno, A. Diaspro, R. Cingolani, A. Athanassiou, "Magnetic Force Microscopy and Energy Loss Imaging of Superparamagnetic Iron Oxide Nanoparticles," Sci. Rep. 1 (2011) 202. doi:10.1038/srep00202. 


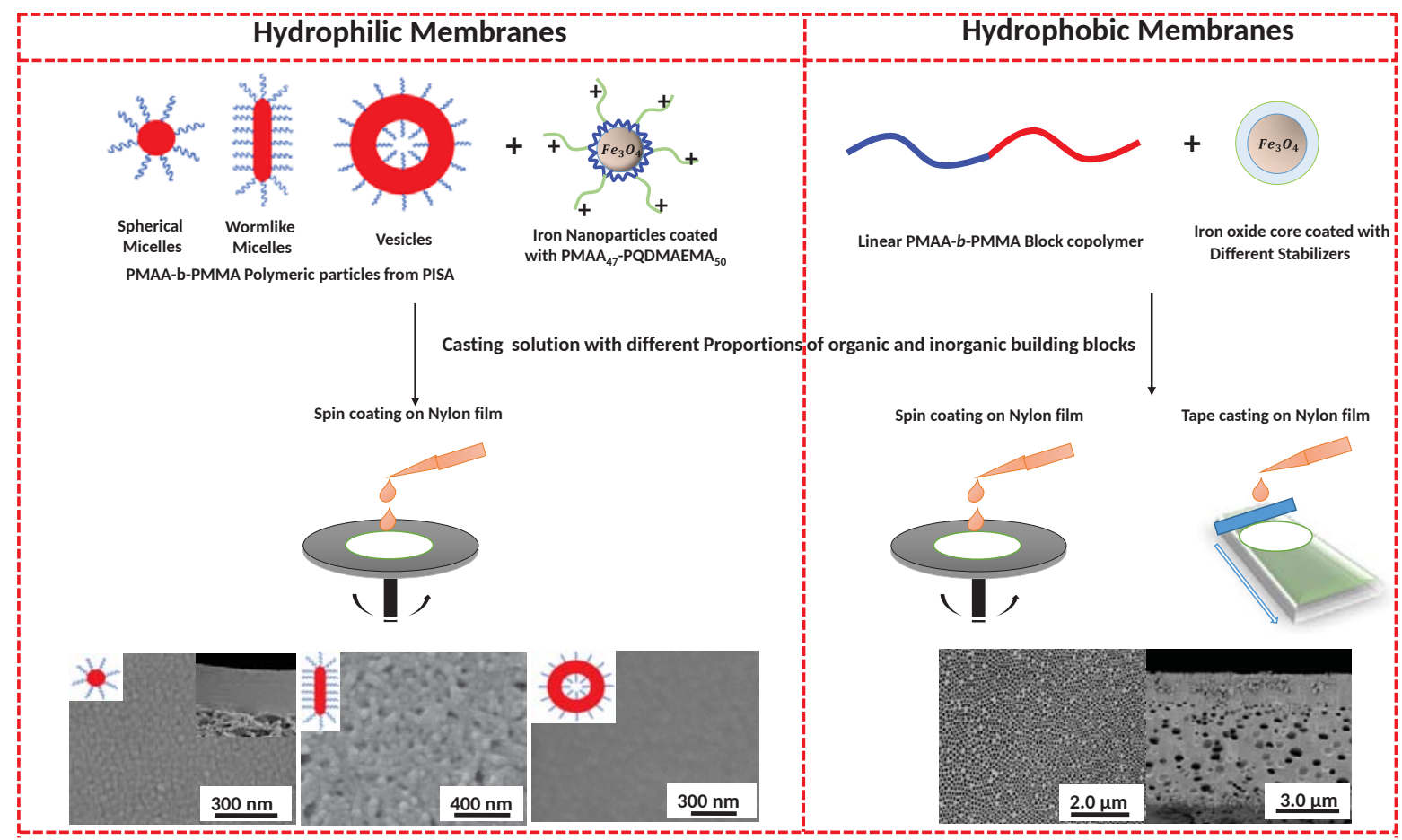

Fig. 1. Schematic representation of the fabrication of hydrophilic and hydrophobic membranes (Adapted from Ref 37 and 38)

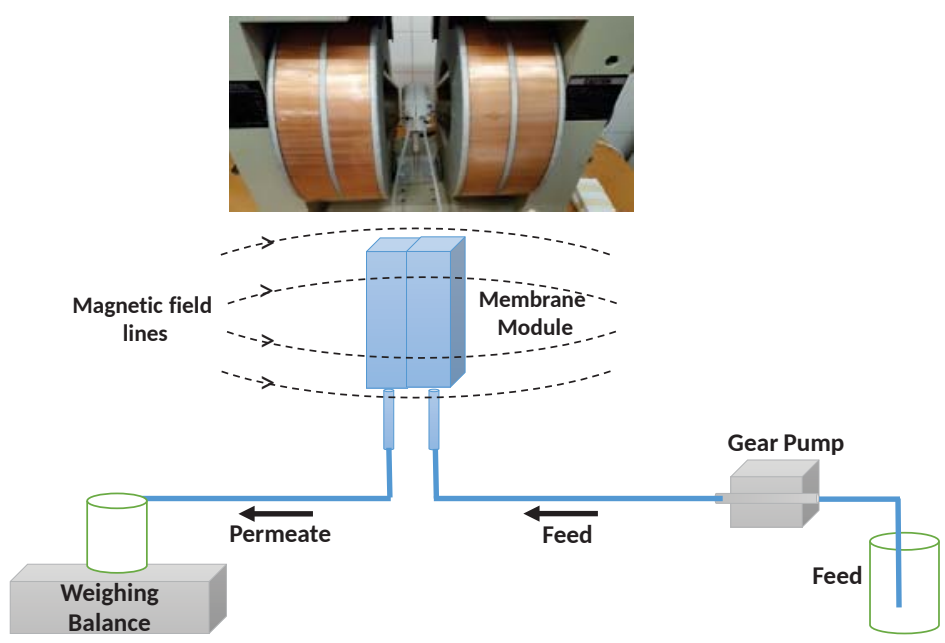

Fig. 2. Schematic representation of cross-flow filtration setup without retentate recycle. 

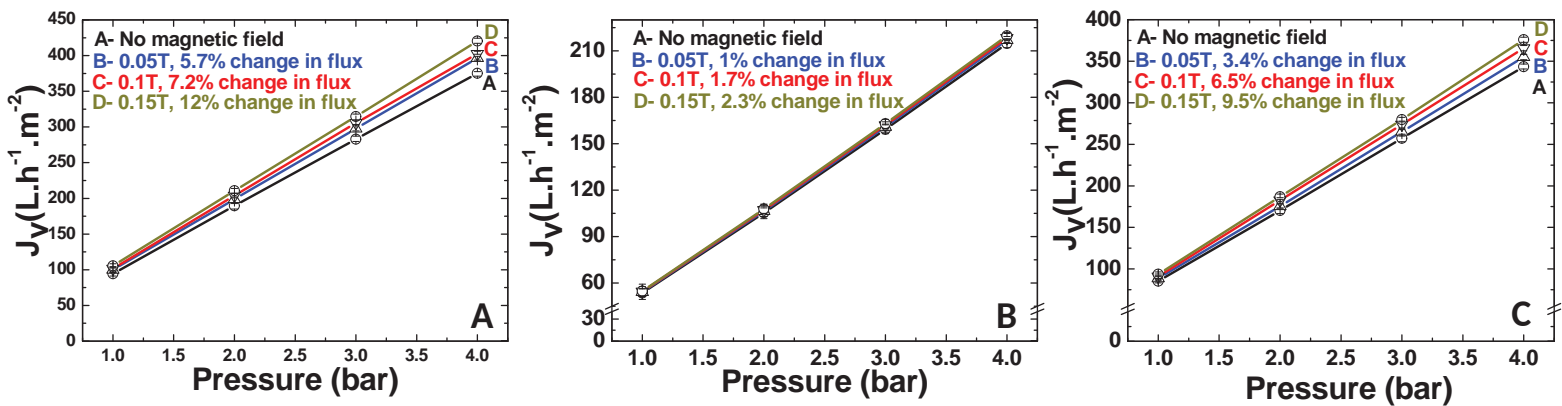

Fig. 3. Permeate flux values obtained for membranes with (A) spherical (B) vermicular (C) vesicular structured top layers, in dead-end mode, in the absence and presence of magnetic field at intensities up to $0.15 \mathrm{~T}$.
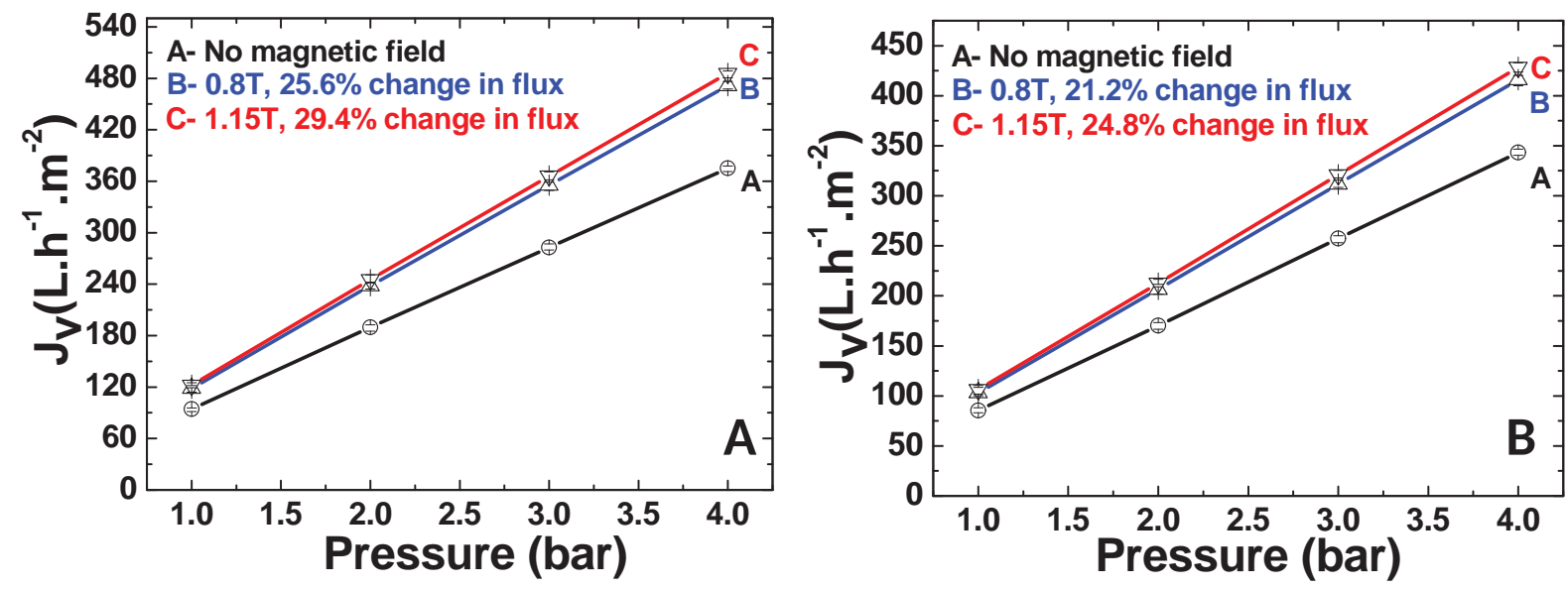

Fig. 4. Permeate flux profiles obtained for membranes with (A) sphere-like structured top layer (B) vesicle-like structured top layer based membranes, in cross-flow mode in the absence and presence of magnetic field with intensities up to $1.15 \mathrm{~T}$. 


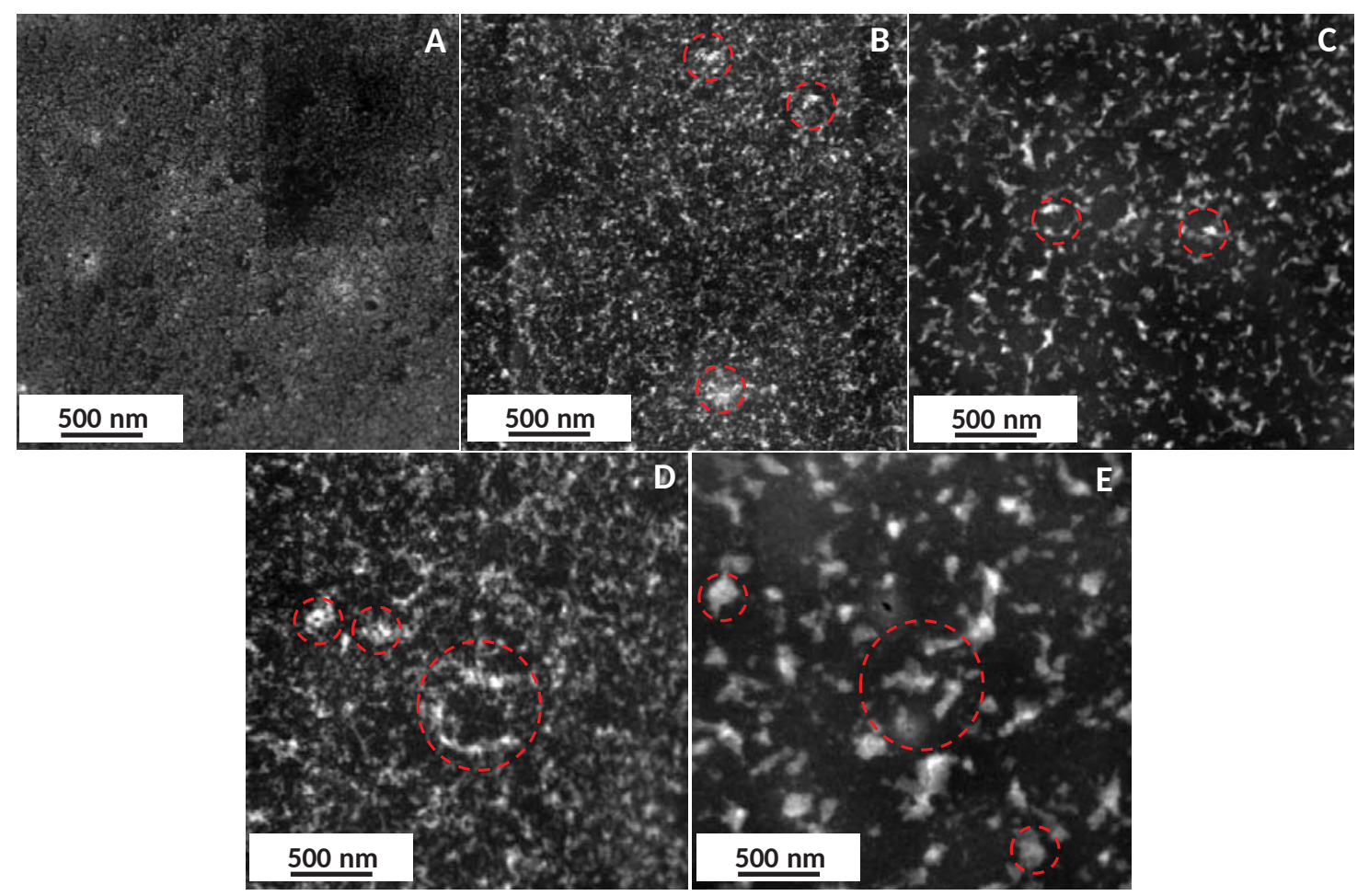

Fig. 5. STEM-HAADF images of a sphere-like structured top layer with INPs acquired immediately upon exposure to magnetic field intensities of (A) No field, (B) $0.2 \mathrm{~T}$, (C) $0.4 \mathrm{~T}$, (D) $0.6 \mathrm{~T}$ and (E) $1.15 \mathrm{~T}$. (Red zones showing some of the agglomeration spotted). 

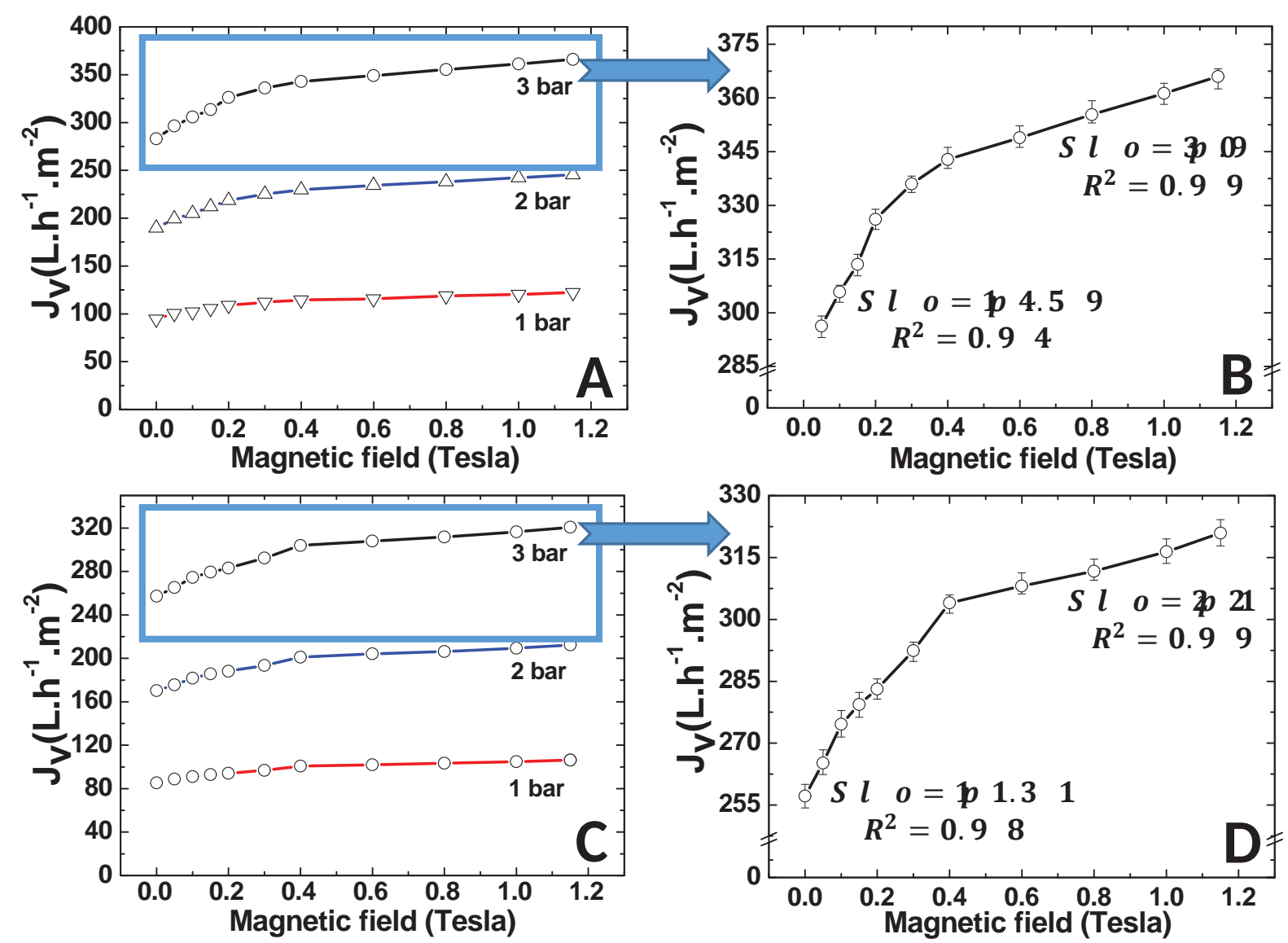

Fig. 6. Variation of the permeate flux versus magnetic field intensity at different transmembrane pressures for membranes with (A) sphere-like structured top layer and (C) vesicle-like structured top layers. The profiles obtained at transmembrane pressure of 3 bar are zoomed for membranes with (B) sphere-like structured top layer and (D) vesicle-like structured top layer 

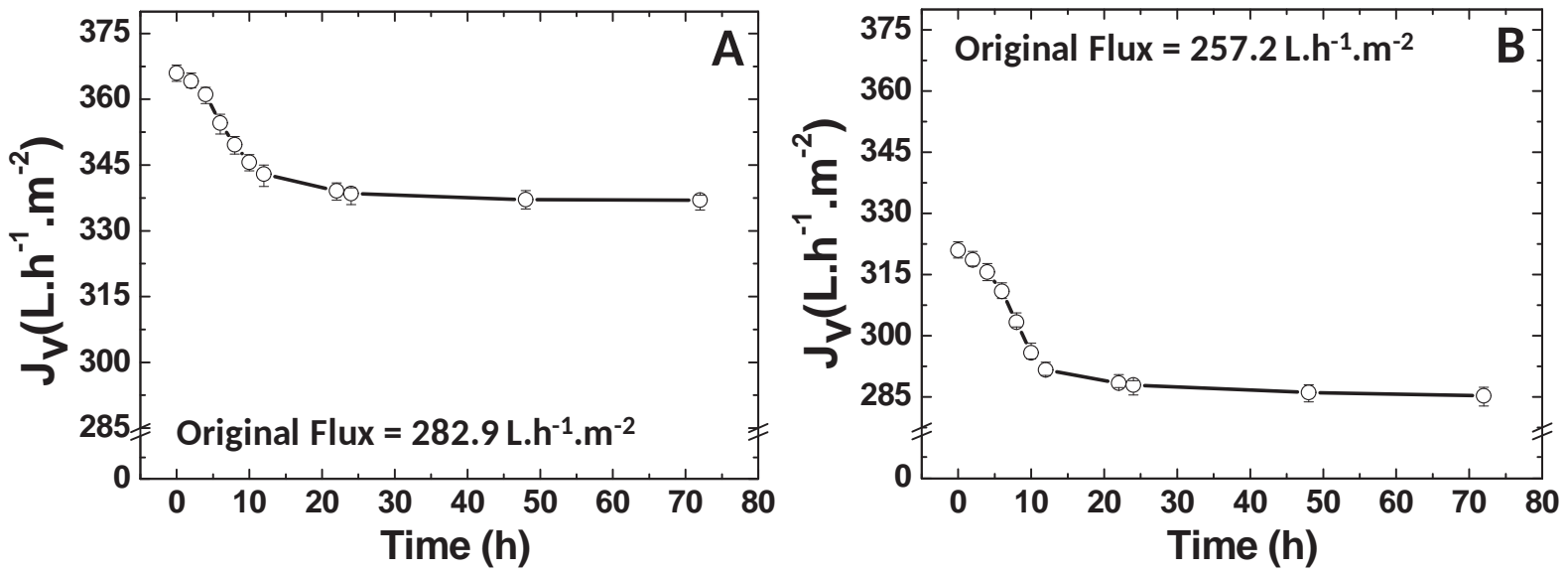

Fig. 7. Magnetic relaxation curve obtained for membranes with (A) sphere-like structured top layer and (B) vesiclelike structured top layer carried out at a transmembrane pressure of 3 bar after removal of magnetic field intensity of $1.15 \mathrm{~T}$.

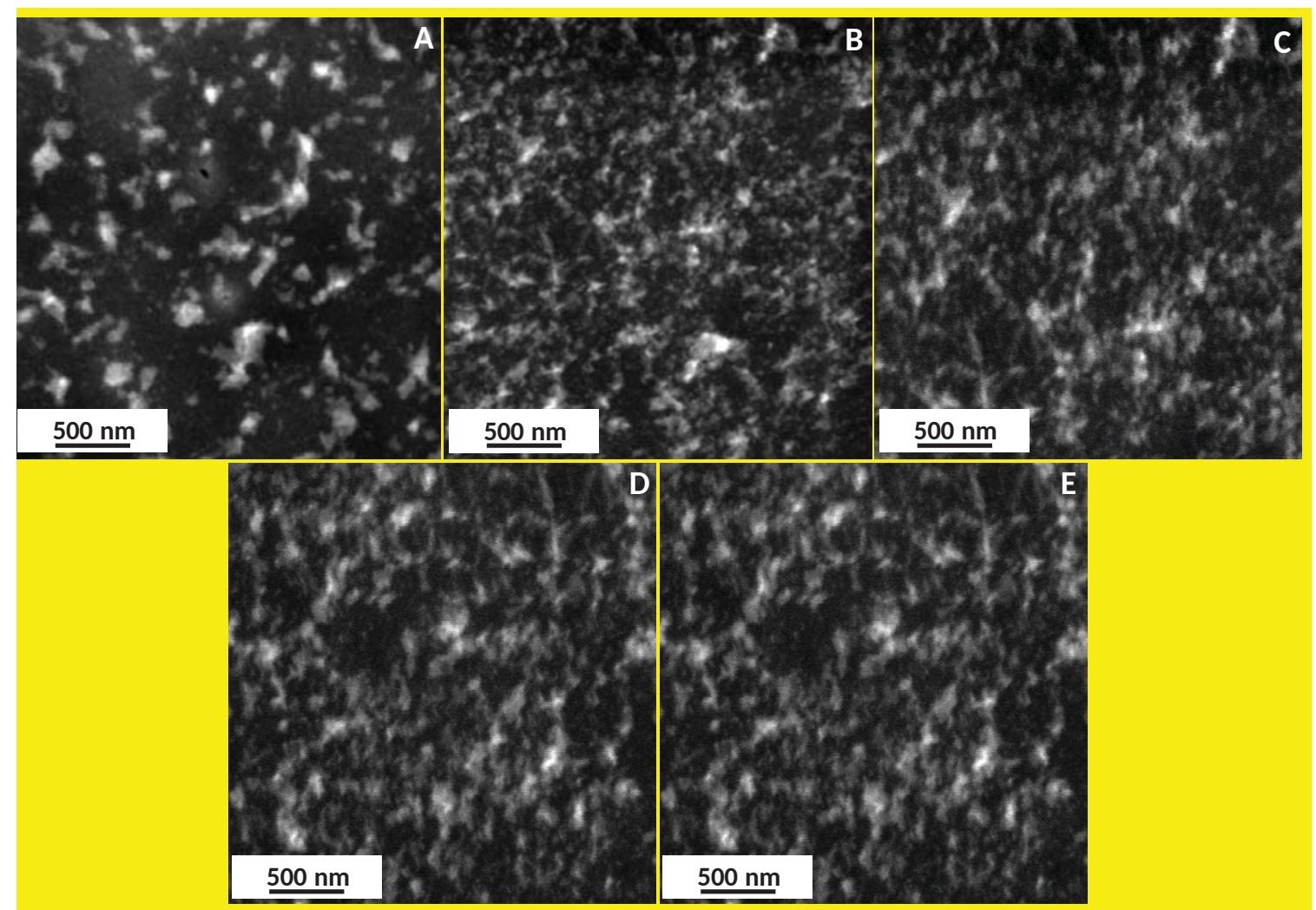

Fig. 8. STEM-HAADF images of a sphere-like structured top layer with INPs after a magnetic relaxation time of (A) $0 \mathrm{~h},(\mathrm{~B}) 10 \mathrm{~h},(\mathrm{C}) 20 \mathrm{~h}$, (D) $50 \mathrm{~h}$ and (E) $70 \mathrm{~h}$. 

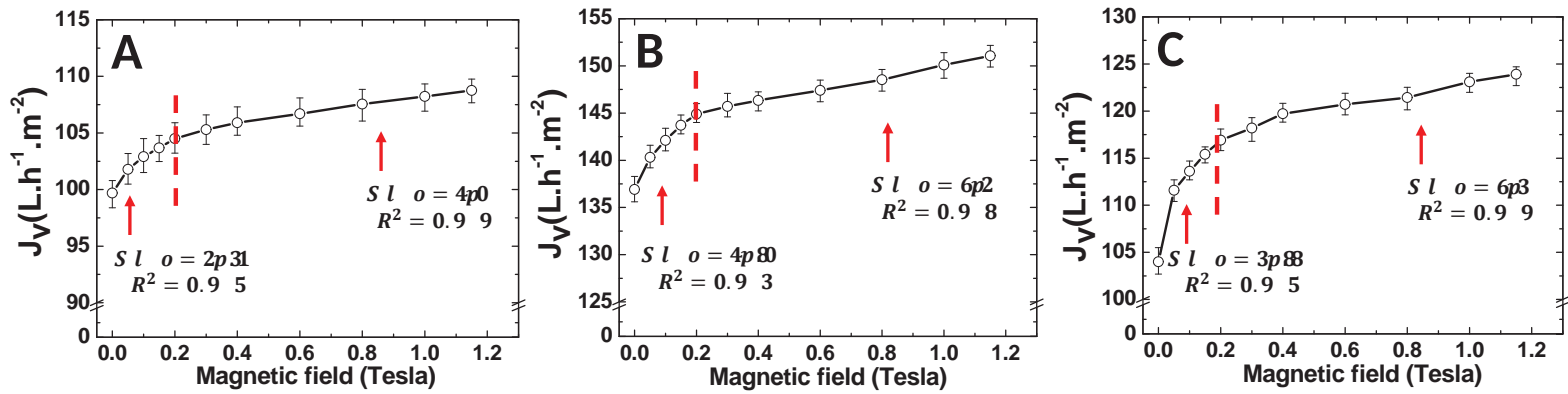

Fig. 9. Variation of the permeate flux versus magnetic field for tape cast membranes containing (A) $\mathrm{PMAA}_{47}(\mathrm{~B})$ PMAA $_{47}-b$-PQDMAEMA 50 (C) DMSA-coated iron oxide nanoparticles at transmembrane pressure of 4 bar.
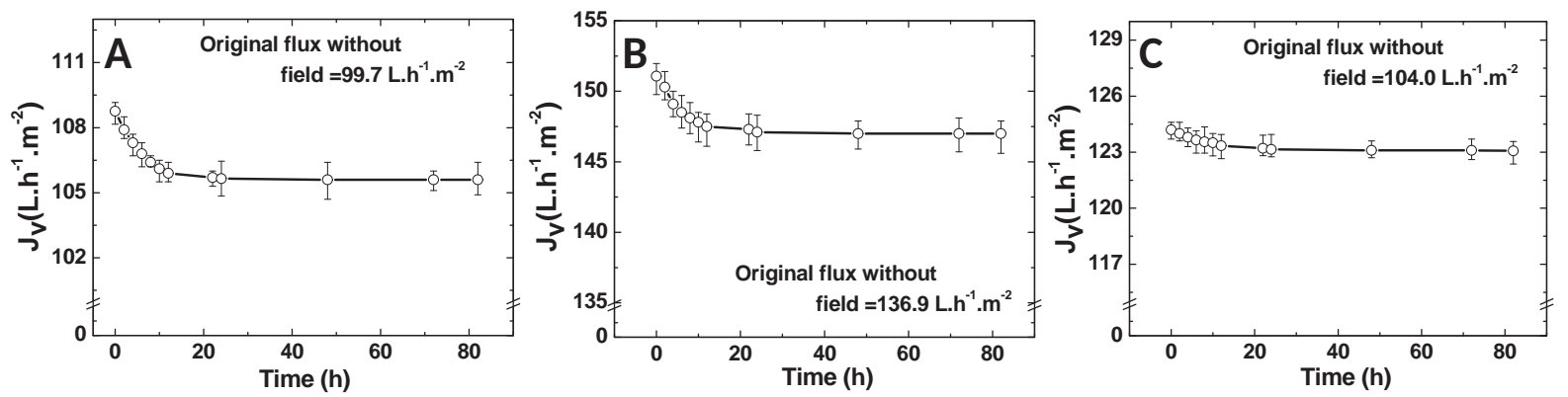

Fig. 10. Magnetic relaxation curve obtained for membranes containing (A) PMAA $_{47}$ (B) PMAA $47-b$-PQDMAEMA 50 (C) DMSA-coated iron oxide nanoparticles at 4 bar of transmembrane pressure with a magnetic field intensity of $1.15 \mathrm{~T}$. 

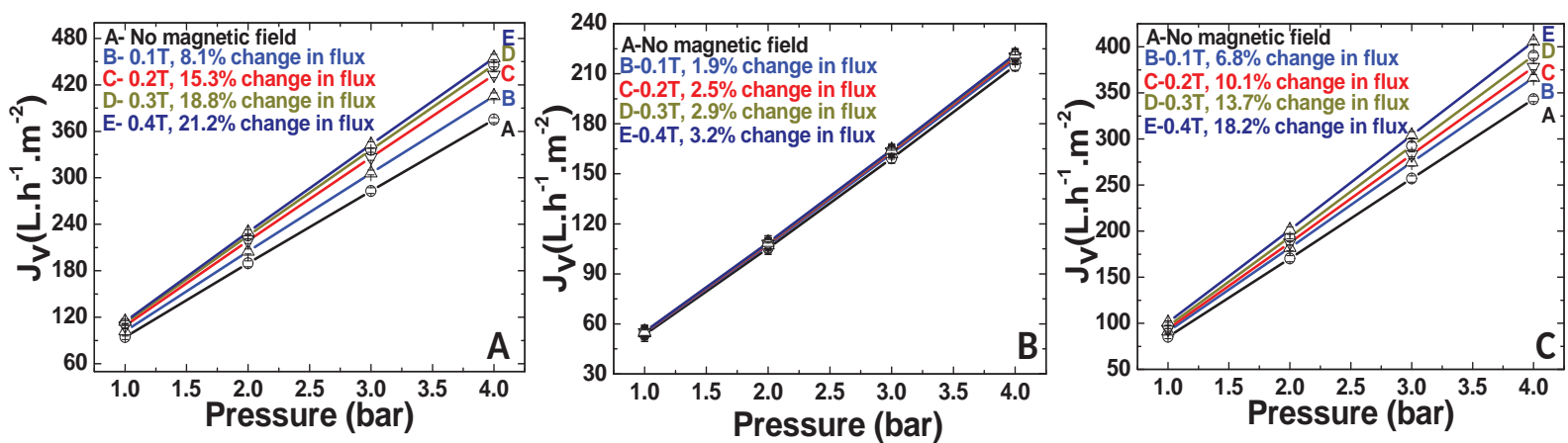

Fig. S1. Permeate flux values obtained for membranes containing (A) spherical (B) vermicular and (C) vesicular structured top layers, in cross-flow mode, in the absence and presence of magnetic field intensities up to $0.4 \mathrm{~T}$.
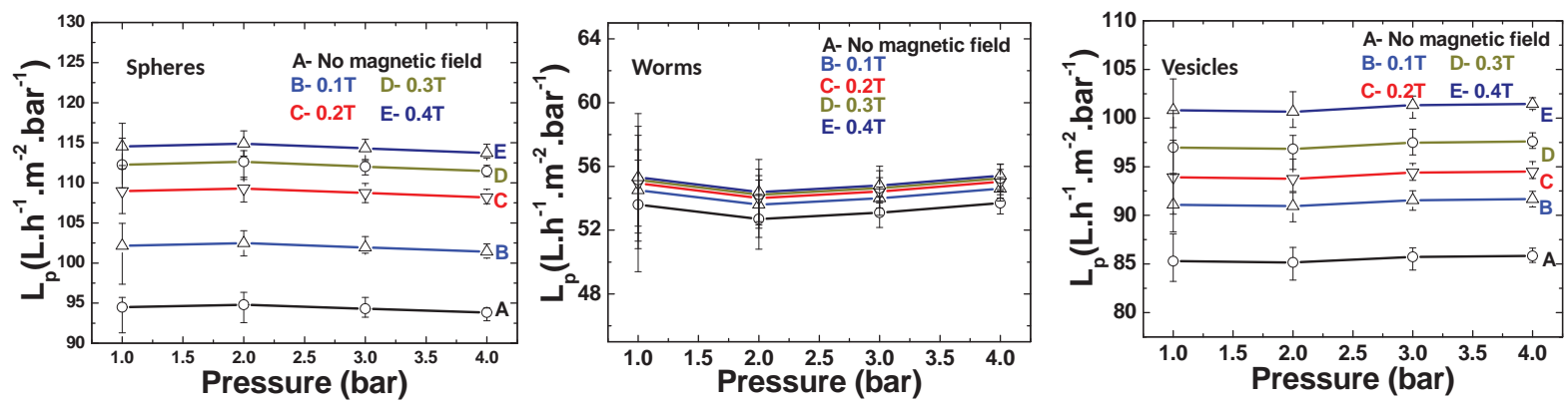

Fig. S2. Hydraulic permeability profile obtained for membranes containing sphere, worm and vesicle-like structured top layers, in cross-flow mode, in the absence and presence of magnetic field intensities up to $0.4 \mathrm{~T}$. 

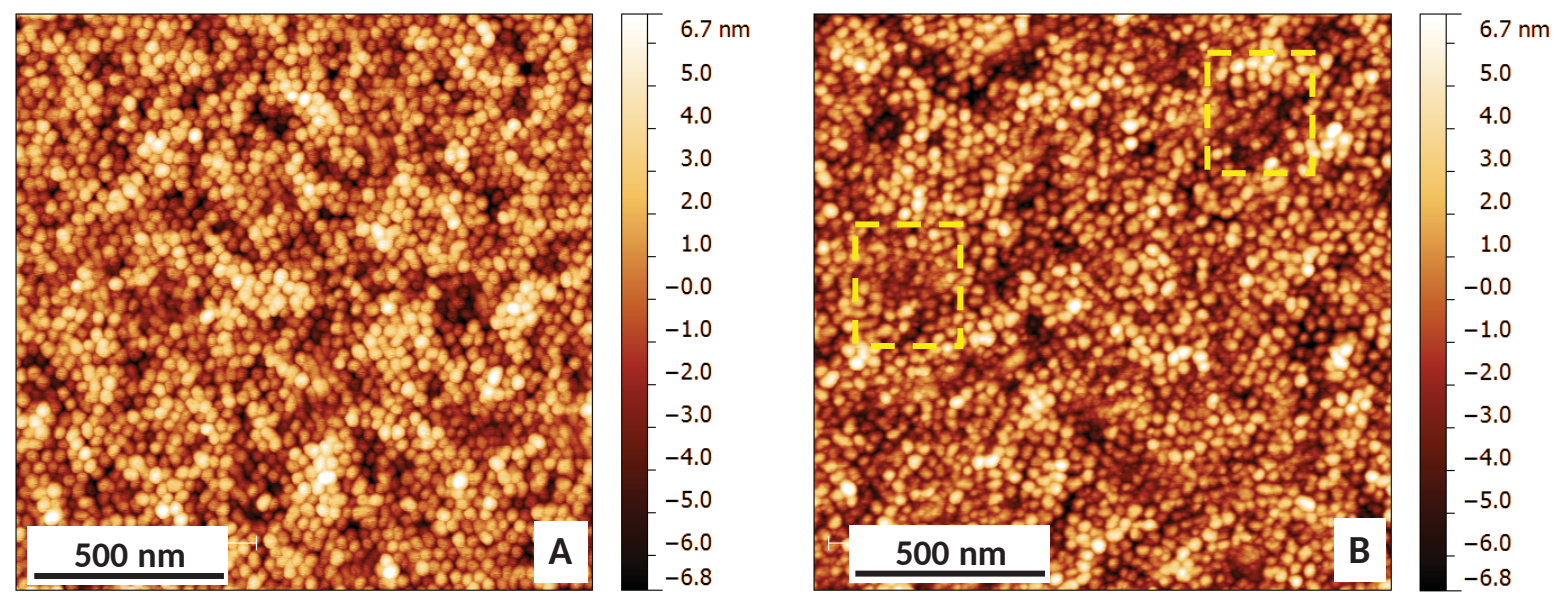

Fig. S3. The AFM images of the membranes with sphere-like structured top layers acquired (A) before and (B) after applying the magnetic field at $1.15 \mathrm{~T}$.

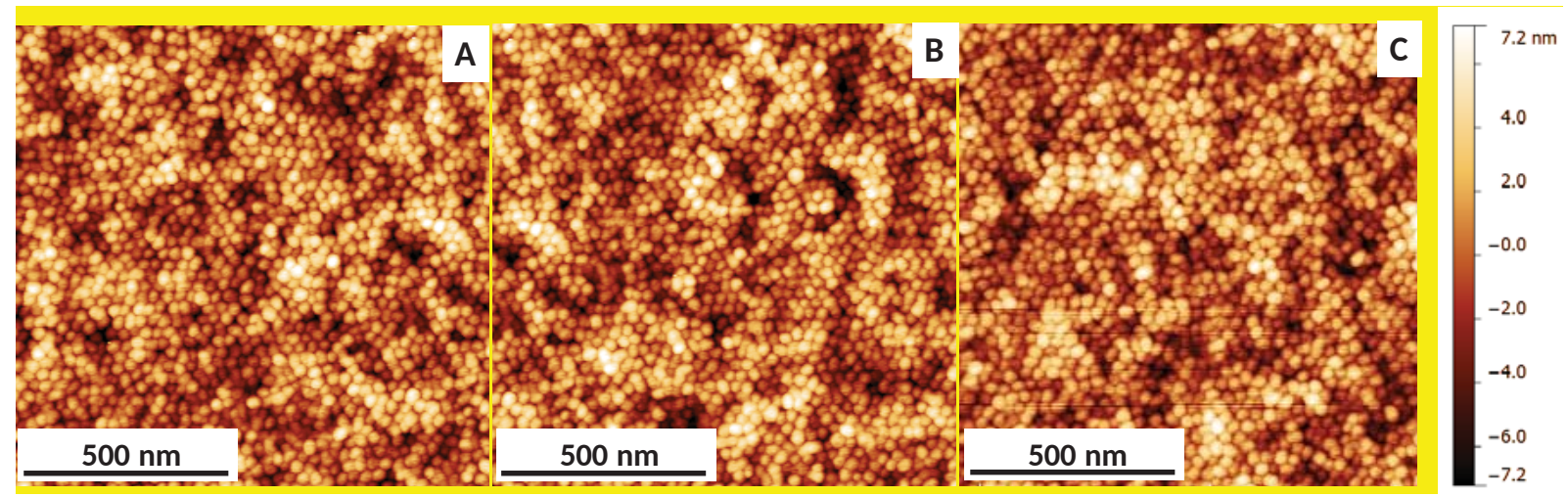

Fig. S4. The AFM images of a membrane sample containing a sphere-like structured top layer with INPs acquired under (A) No magnetic field and in the presence of (B) $0.4 \mathrm{~T}$ and (C) $1.15 \mathrm{~T}$ magnetic field intensity. 


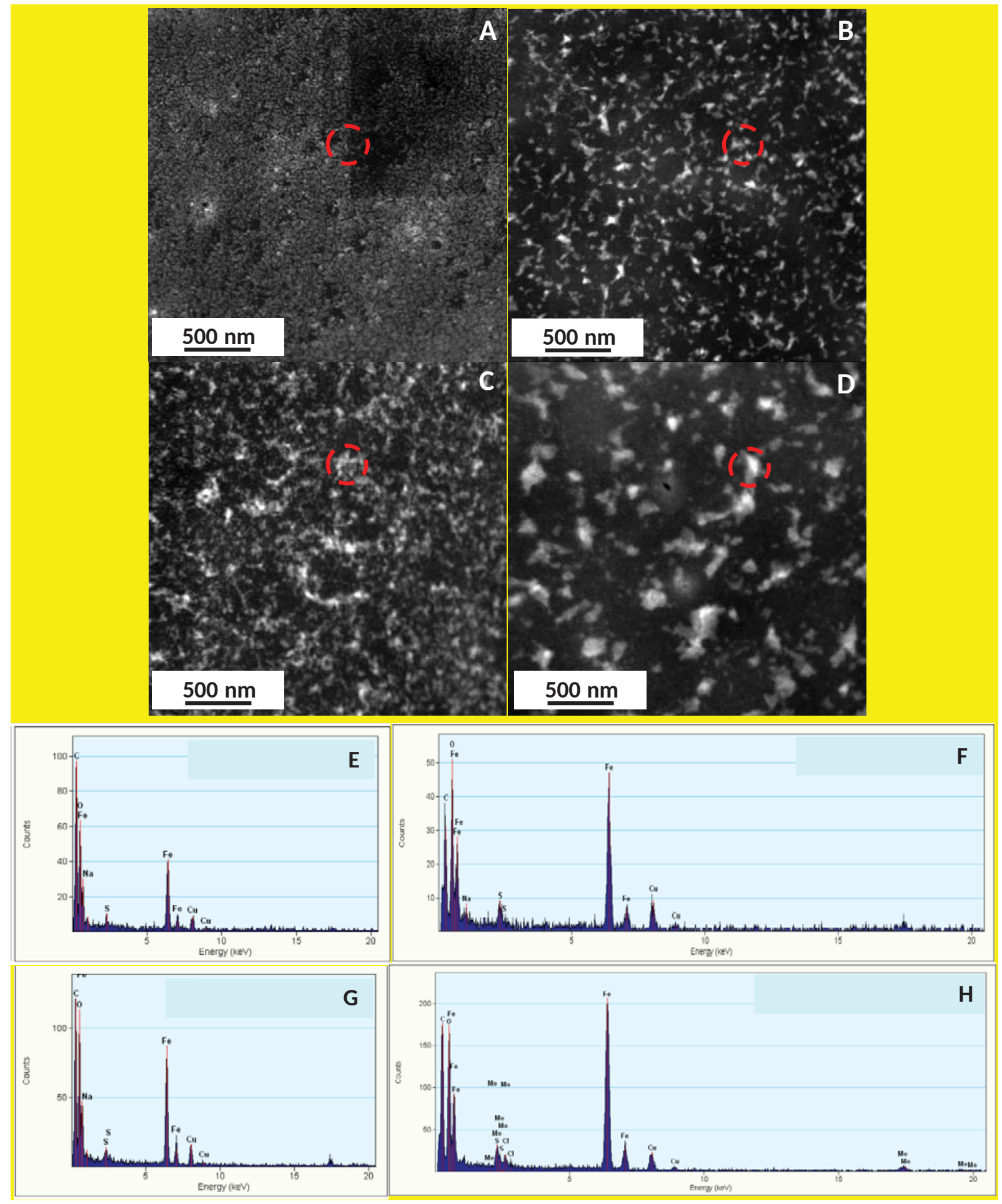

Fig. S5. STEM-HAADF (A, B, C and D) and respective EDS (E, F, G and H) images of a sphere-like structured top layer with INPs acquired immediately upon exposure to magnetic field intensities of: (A and E) No field, (B and F) $0.4 \mathrm{~T}$, (C and $\mathrm{G}) 0.6 \mathrm{~T}$ and $(\mathrm{D}$ and $\mathrm{H}) 1.15 \mathrm{~T}$. (Red zones correspond to the regions analyzed by EDS probe). 

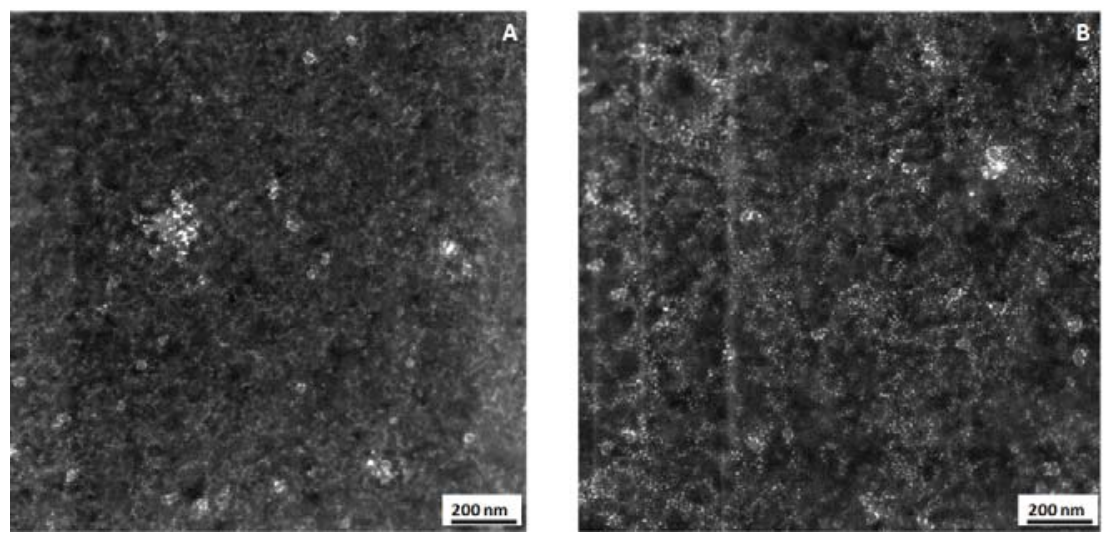

Fig. S6. STEM analysis of copolymer nanoparticle solution containing DMSA-coated iron oxide nanoparticles (A) no magnetic field (B) magnetic field at $0.4 \mathrm{~T}$. 
Table 1. The performance of hydrophobic MMMs under magnetic field prepared through NIPS technique.

\begin{tabular}{|c|c|c|c|c|}
\hline $\begin{array}{c}\text { Membrane } \\
\text { type }\end{array}$ & $\begin{array}{c}\text { Type of stabilizer used for INPs } \\
\text { coating }\end{array}$ & $\begin{array}{c}\text { Flux at } 0 \mathrm{~T} \\
\left(\mathrm{~L} \cdot \mathrm{h}^{-1} \cdot \mathrm{m}^{-2}\right)\end{array}$ & $\begin{array}{c}\text { Flux at } 1.15 \mathrm{~T} \\
\left(\mathrm{~L} \cdot \mathrm{h}^{-1} \cdot \mathrm{m}^{-2}\right)\end{array}$ & $\begin{array}{c}\text { Flux change } \\
(\%)\end{array}$ \\
\hline \multirow{3}{*}{ Tape casting } & PMAA $_{47}$ & 99.7 & 108.8 & 8.3 \\
\cline { 2 - 5 } & $\mathrm{PMAA}_{47}-b-\mathrm{PQDMAEMA}_{50}$ & 136.9 & 151.1 & 9.4 \\
\cline { 2 - 5 } & DMSA $^{\text {Spin coating }}$ & 104.0 & 124.0 & 16.1 \\
\cline { 2 - 5 } & PMAA $_{47}$ & 205.9 & 228.3 & 9.8 \\
\cline { 2 - 5 } & PMAA $_{47}-b-$ PQDMAEMA $_{50}$ & 166.3 & 186.5 & 10.8 \\
\cline { 2 - 5 } & DMSA & 155.5 & 186.9 & 16.8 \\
\hline
\end{tabular}

Table S1. Comparison of the filtration fluxes, J, obtained in dead-end filtration and cross-flow filtration for membranes with sphere-like structured top layer

$\begin{array}{ccccc}\begin{array}{c}\text { Pressure } \\ \text { (bar) }\end{array} & \begin{array}{c}\mathbf{0 . 0 5} \mathbf{T} \\ \text { Dead-end }\end{array} & \begin{array}{c}\mathbf{0 . 0 5} \mathbf{T} \\ \text { Cross-flow }\end{array} & \begin{array}{c}\mathbf{0 . 1 5} \mathbf{T} \\ \text { Dead-end }\end{array} & \begin{array}{c}\mathbf{0 . 1 5} \mathbf{T} \\ \text { Cross-flow }\end{array} \\ & \begin{array}{c}\mathbf{J}_{\mathrm{v}} \\ \left(\mathrm{L} \cdot \mathrm{h}^{-1} \cdot \mathrm{m}^{-2}\right)\end{array} & \begin{array}{c}\mathbf{J}_{\mathrm{v}} \\ \left(\mathrm{L} \cdot \mathrm{h}^{-1} \cdot \mathrm{m}^{-2}\right)\end{array} & \begin{array}{c}\mathbf{J}_{\mathrm{v}} \\ \left(\mathrm{L}^{-1} \cdot \mathrm{h}^{-1} \cdot \mathrm{m}^{-2}\right)\end{array} & \begin{array}{c}\mathbf{J}_{\mathrm{v}} \\ \left(\mathrm{L}^{-1} \cdot \mathrm{h}^{-2}\right)\end{array} \\ \mathbf{1} & 99.9 & 100.4 & 105.6 & 108.9 \\ \mathbf{2} & 198.7 & 199.2 & 210.6 & 211.9 \\ \mathbf{3} & 297.6 & 296.3 & 314.6 & 313.5 \\ \mathbf{4} & 396.6 & 393.3 & 420.3 & 423.6\end{array}$

Table S2. Comparison of the filtration fluxes, J, obtained in dead-end filtration and cross-flow filtration for membranes with worm-like structured top layer

\begin{tabular}{|c|c|c|c|c|}
\hline \multirow[t]{2}{*}{$\begin{array}{l}\text { Pressure } \\
\text { (bar) }\end{array}$} & $\begin{array}{c}0.05 \mathrm{~T} \\
\text { Dead-end }\end{array}$ & $\begin{array}{c}0.05 \mathrm{~T} \\
\text { Cross-flow }\end{array}$ & $\begin{array}{c}0.15 \mathrm{~T} \\
\text { Dead-end }\end{array}$ & $\begin{array}{c}0.15 \mathrm{~T} \\
\text { Cross-flow }\end{array}$ \\
\hline & $\begin{array}{c}\mathrm{J}_{\mathrm{v}} \\
\left(\mathrm{L} \cdot \mathrm{h}^{-1} \cdot \mathrm{m}^{-2}\right)\end{array}$ & $\begin{array}{c}\mathrm{J}_{\mathrm{v}} \\
\left(\mathrm{L} \cdot \mathrm{h}^{-1} \cdot \mathrm{m}^{-2}\right)\end{array}$ & $\begin{array}{c}\mathrm{J}_{\mathrm{v}} \\
\left(\mathrm{L} \cdot \mathrm{h}^{-1} \cdot \mathrm{m}^{-2}\right)\end{array}$ & $\begin{array}{c}\mathrm{J}_{\mathrm{v}} \\
\left(\mathrm{L} \cdot \mathrm{h}^{-1} \cdot \mathrm{m}^{-2}\right)\end{array}$ \\
\hline 1 & 54.2 & 57.2 & 54.8 & 54.1 \\
\hline 2 & 106.7 & 104.9 & 107.8 & 108.8 \\
\hline 3 & 160.8 & 162.3 & 162.9 & 161.6 \\
\hline 4 & 216.5 & 215.5 & 219.6 & 220.0 \\
\hline
\end{tabular}


Table S3. Comparison of the filtration fluxes, J, obtained in dead-end filtration and cross-flow filtration for membranes with vesicle-like structured top layer

$\begin{array}{ccccc}\begin{array}{c}\text { Pressure } \\ \text { (bar) }\end{array} & \begin{array}{c}\mathbf{0 . 0 5} \mathbf{T} \\ \text { Dead-end }\end{array} & \begin{array}{c}\mathbf{0 . 0 5} \mathbf{T} \\ \text { Cross-flow }\end{array} & \begin{array}{c}\mathbf{0 . 1 5} \mathbf{T} \\ \text { Dead-end }\end{array} & \begin{array}{c}\mathbf{0 . 1 5} \mathbf{T} \\ \text { Cross-flow }\end{array} \\ & \begin{array}{c}\mathbf{J}_{\mathrm{v}} \\ \left(\mathrm{L}^{-1} \cdot \mathrm{m}^{-2}\right)\end{array} & \begin{array}{c}\mathbf{J}_{\mathrm{v}} \\ \left(\mathrm{L} \cdot \mathrm{h}^{-1} \cdot \mathrm{m}^{-2}\right)\end{array} & \begin{array}{c}\mathrm{J}_{\mathrm{v}} \\ \left(\mathrm{L}^{-1} \cdot \mathrm{h}^{-2} \cdot \mathrm{m}^{-2}\right)\end{array} & \begin{array}{c}\mathbf{J}_{\mathrm{v}} \\ \left(\mathrm{L}^{-1} \cdot \mathrm{h}^{-1} \cdot \mathrm{m}^{-2}\right)\end{array} \\ \mathbf{1} & 88.6 & 88.8 & 93.7 & 94.05 \\ \mathbf{2} & 175.6 & 173.6 & 187.0 & 188.1 \\ \mathbf{3} & 265.2 & 267.1 & 279.7 & 279.5 \\ \mathbf{4} & 354.9 & 356.6 & 375.8 & 374.9\end{array}$

Table S4. Effect of magnetic field on permeate flux: slope and $\mathrm{R}^{2}$ values for membrane with sphere-like and vesicle-like structured top layer at a transmembrane pressure of 1 and 2 bar.

\begin{tabular}{|c|c|c|c|c|}
\hline Membrane Type & $\begin{array}{c}\text { Transmembrane } \\
\text { pressure } \\
\text { (bar) }\end{array}$ & Magnetic field & Slope & $\mathrm{R}^{2}$ \\
\hline \multirow{3}{*}{$\begin{array}{c}\text { Sphere-like structured } \\
\text { top layer }\end{array}$} & 1 & 0 to $0.4 \mathrm{~T}$ & 48.3 & 0.94 \\
\cline { 2 - 4 } & 2 & 0.4 to $1.15 \mathrm{~T}$ & 10.6 & 0.98 \\
\cline { 2 - 4 } & \multirow{2}{*}{$\begin{array}{c}\text { Vesicle-like structured } \\
\text { top layer }\end{array}$} & 0 to $0.4 \mathrm{~T}$ & 89.2 & 0.94 \\
\cline { 2 - 4 } & \multirow{2}{*}{2} & 0 to $1.15 \mathrm{~T}$ & 20.6 & 0.99 \\
\cline { 2 - 4 } & & 0.4 to $1.15 \mathrm{~T}$ & 36.0 & 0.97 \\
\cline { 2 - 4 } & & 0 to $0.4 \mathrm{~T}$ & 7.3 & 0.97 \\
\hline
\end{tabular}




\section{Supporting information}

\section{Block copolymer based novel magnetic mixed matrix membranes- Magnetic modulation of water permeation by irreversible structural changes}

Lakshmeesha Upadhyayaa,d,e, Mona Semsarilara, Damien Quemenera, Rodrigo Fernández-Pachecob, Gema Martinez $^{\mathrm{c}, \mathrm{d}}$, Reyes Malladad ${ }^{\mathrm{d}}$ Isabel M. Coelhoso ${ }^{\mathrm{e}}$, Carla A. M. Portugale ${ }^{\star}$, João G. Crespo ${ }^{\mathrm{e}}$

a Institut Européen des Membranes/ Université of Montpellier, Place E.Bataillon CC047, 34095 Montpellier, France

b Laboratorio de Microscopías Avanzadas (LMA), Instituto de Nanociencia de Aragón (INA), Edificio I+D, Campus Rio Ebro.Universidad de Zaragoza, 50018, Zaragoza Spain

${ }^{\mathrm{C}}$ Networking Research Centre on Bioengineering, Biomaterials and Nanomedicine, CIBER-BBN, 28029 Madrid, Spain

dDepartment of Chemical and Environmental Engineering and Aragon Nanoscience Institute, Campus Río Ebro, C/ Mariano Esquillor s/n ,50018 Zaragoza, Spain

e LAQV- REQUIMTE, Departamento de Química, Faculdade de Ciências e Tecnologia, Universidade Nova de Lisboa, Campus de Caparica, 2829-516 Caparica, Portugal

Table S1. Comparison of the filtration fluxes, J, obtained in dead-end filtration and cross-flow filtration for membranes with sphere-like structured top layer

$\begin{array}{ccccc}\begin{array}{c}\text { Pressure } \\ \text { (bar) }\end{array} & \begin{array}{c}\mathbf{0 . 0 5} \mathbf{T} \\ \text { Dead-end }\end{array} & \begin{array}{c}\mathbf{0 . 0 5} \mathbf{T} \\ \text { Cross-flow }\end{array} & \begin{array}{c}\mathbf{0 . 1 5} \mathbf{T} \\ \text { Dead-end }\end{array} & \begin{array}{c}\mathbf{0 . 1 5} \mathbf{T} \\ \text { Cross-flow }\end{array} \\ & \begin{array}{c}\mathbf{J}_{\mathrm{v}} \\ \left(\mathrm{L} \cdot \mathrm{h}^{-1} \cdot \mathrm{m}^{-2}\right)\end{array} & \begin{array}{c}\mathbf{J}_{\mathrm{v}} \\ \left(\mathrm{L} \cdot \mathrm{h}^{-1} \cdot \mathrm{m}^{-2}\right)\end{array} & \begin{array}{c}\mathbf{J}_{\mathrm{v}} \\ \left(\mathrm{L}_{\mathrm{v}} \mathrm{h}^{-1} \cdot \mathrm{m}^{-2}\right)\end{array} & \begin{array}{c}\mathrm{J}_{\mathrm{v}} \\ \left(\mathrm{L}^{-1} \cdot \mathrm{h}^{-2}\right)\end{array} \\ \mathbf{1} & 99.9 & 100.4 & 105.6 & 108.9 \\ \mathbf{2} & 198.7 & 199.2 & 210.6 & 211.9 \\ \mathbf{3} & 297.6 & 296.3 & 314.6 & 313.5 \\ \mathbf{4} & 396.6 & 393.3 & 420.3 & 423.6\end{array}$

Table S2. Comparison of the filtration fluxes, J, obtained in dead-end filtration and cross-flow filtration for membranes with worm-like structured top layer

$\begin{array}{ccccc}\begin{array}{c}\text { Pressure } \\ \text { (bar) }\end{array} & \begin{array}{c}\mathbf{0 . 0 5} \mathbf{T} \\ \text { Dead-end }\end{array} & \begin{array}{c}\mathbf{0 . 0 5} \mathbf{T} \\ \text { Cross-flow }\end{array} & \begin{array}{c}\mathbf{0 . 1 5} \mathbf{T} \\ \text { Dead-end }\end{array} & \begin{array}{c}\mathbf{0 . 1 5} \mathbf{T} \\ \text { Cross-flow }\end{array} \\ & \begin{array}{c}\mathrm{J}_{\mathrm{v}} \\ \left(\mathrm{L} \cdot \mathrm{h}^{-1} \cdot \mathrm{m}^{-2}\right)\end{array} & \mathrm{J}_{\mathrm{v}} & \mathrm{J}_{\mathrm{v}} & \left(\mathrm{L}^{-1} \cdot \mathrm{h}^{-1} \cdot \mathrm{m}^{-2}\right) \\ \mathbf{1} & 54.2 & 57.2 & \left.\mathrm{~L}^{-2} \mathrm{~h}^{-1} \cdot \mathrm{m}^{-2}\right) & 54.1 \\ \mathbf{2} & 106.7 & 104.9 & 54.8 & 108.8 \\ \mathbf{3} & 160.8 & 162.3 & 107.8 & 161.6 \\ \mathbf{4} & 216.5 & 215.5 & 162.9 & 220.0\end{array}$


Table S3. Comparison of the filtration fluxes, J, obtained in dead-end filtration and cross-flow filtration for membranes with vesicle-like structured top layer

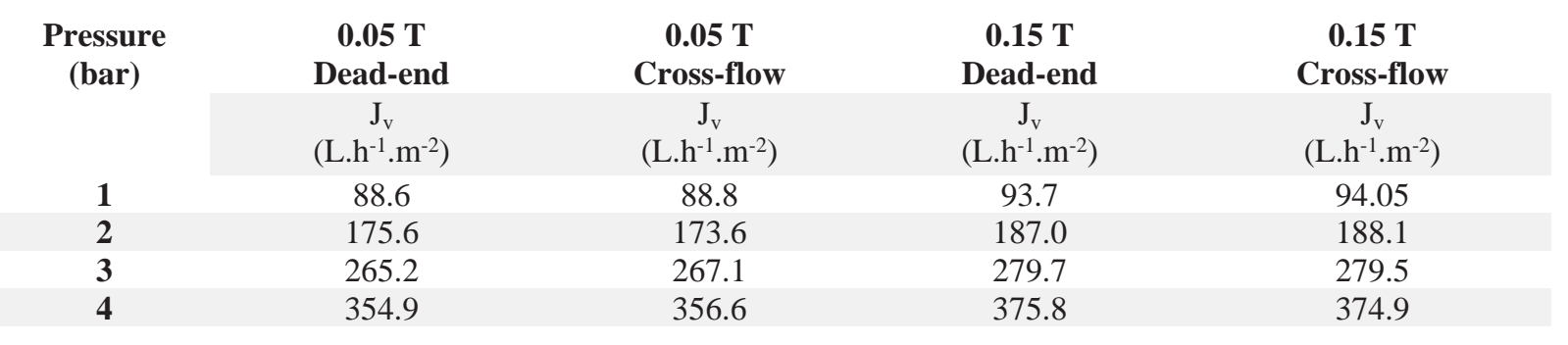
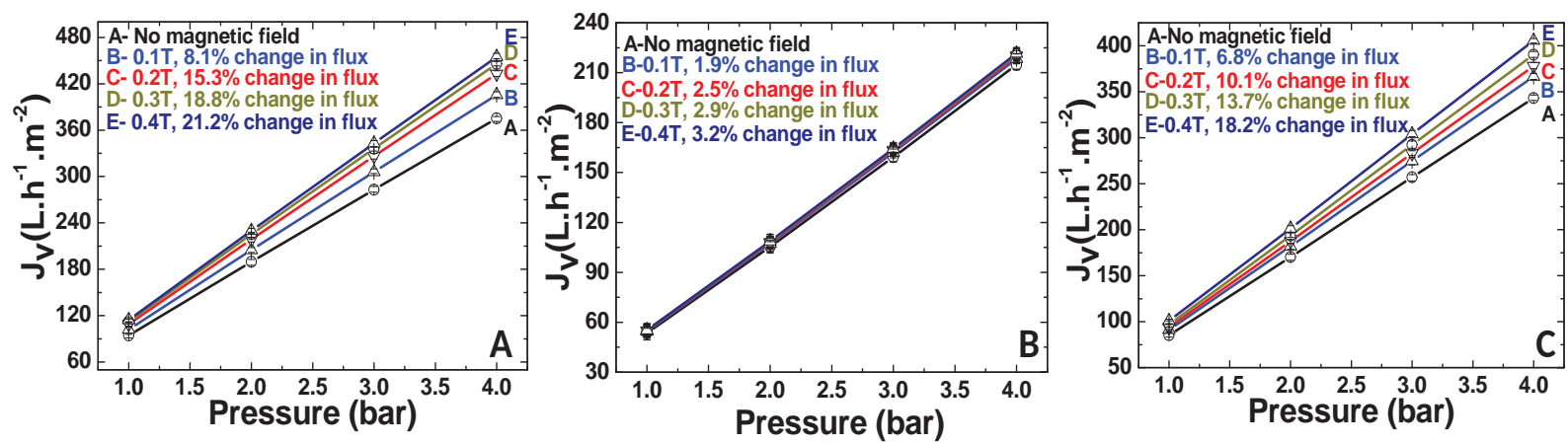

Fig. S1. Permeate flux values obtained for membranes containing (A) spherical (B) vermicular and (C) vesicular structured top layers, in cross-flow mode, in the absence and presence of magnetic field intensities up to $0.4 \mathrm{~T}$.
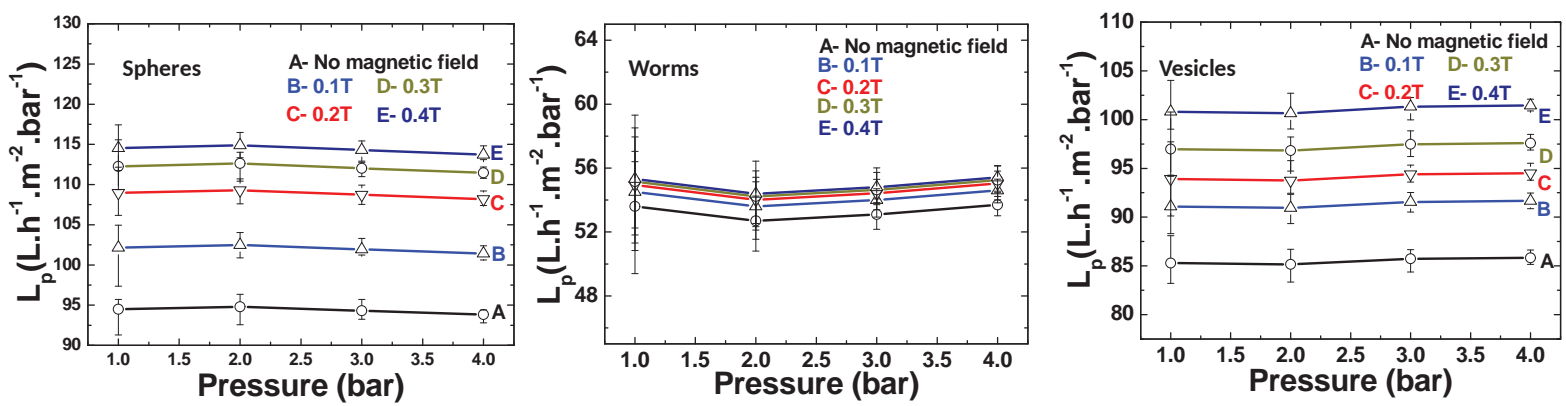

Fig. S2. Hydraulic permeability profile obtained for membranes containing sphere, worm and vesicle-like structured top layers, in cross-flow mode, in the absence and presence of magnetic field intensities up to $0.4 \mathrm{~T}$. 

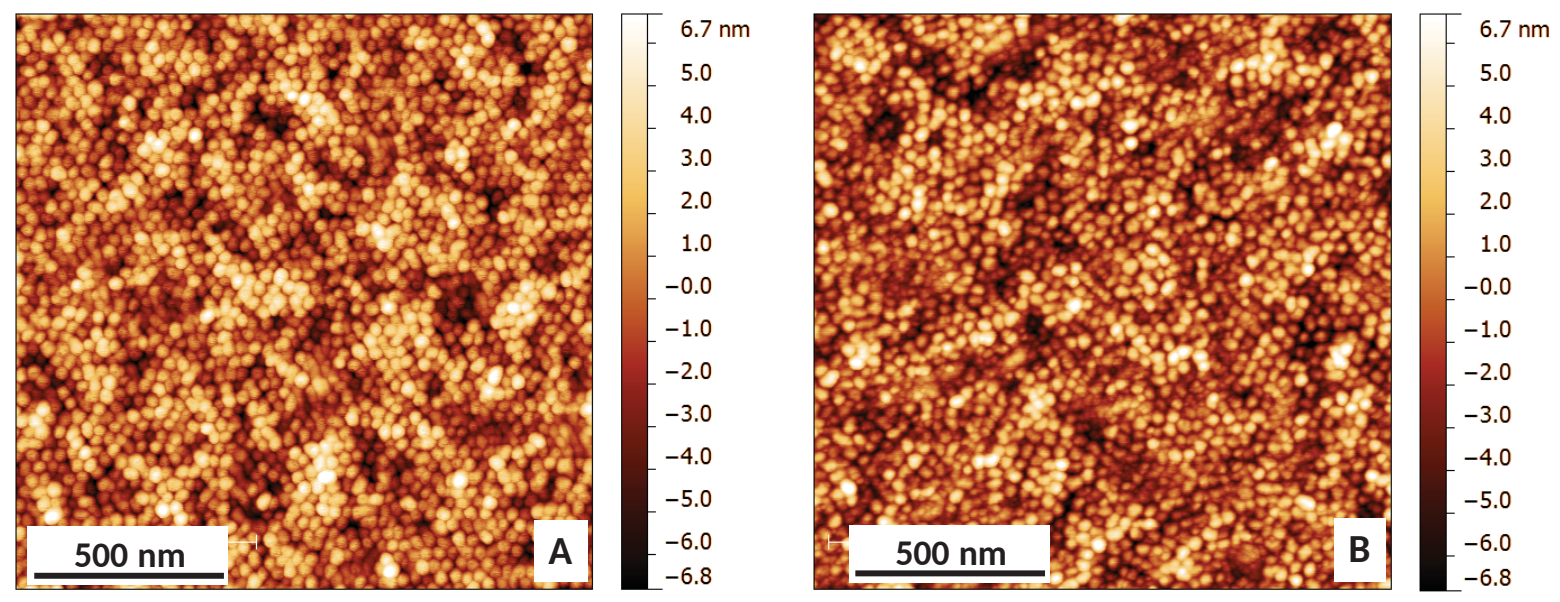

Fig. S3. The AFM images of the membranes (after filtration) with sphere-like structured top layers acquired (A) before and (B) after applying the magnetic field at 1.15T.

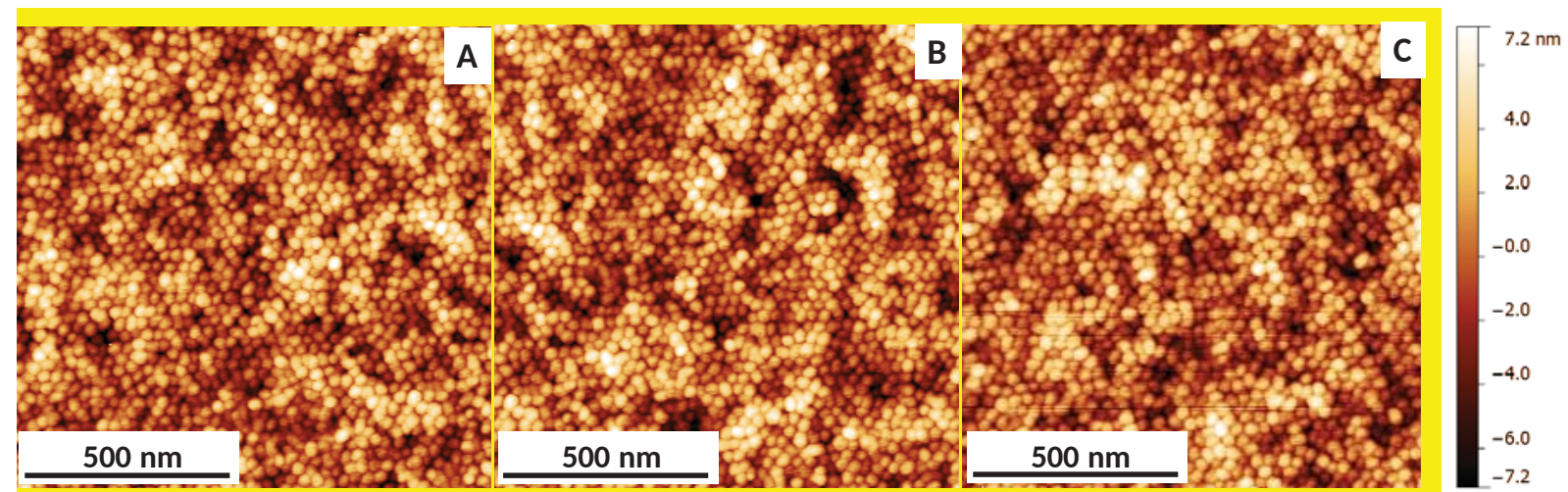

Fig. S4. The AFM images of a membrane sample containing a sphere-like structured top layer with INPs acquired under (A) No magnetic field and in the presence of (B) $0.4 \mathrm{~T}$ and (C) $1.15 \mathrm{~T}$ magnetic field intensity. 


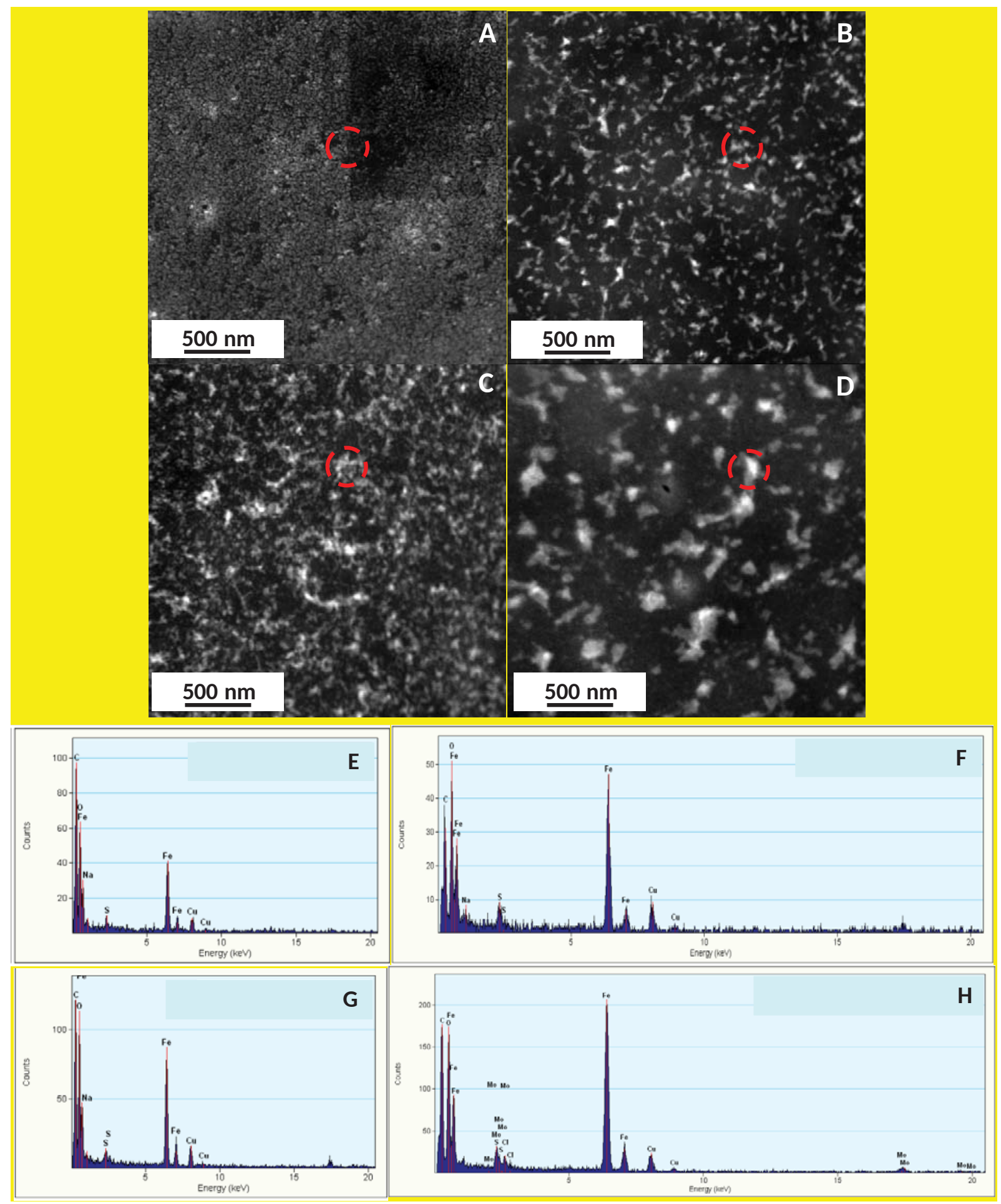

Fig. S5. STEM-HAADF (A, B, C and D) and respective EDS (E, F, G and H) images of a sphere-like structured top layer with INPs acquired immediately upon exposure to magnetic field intensities of: (A and E) No field, (B and F) $0.4 \mathrm{~T}$, (C and G) $0.6 \mathrm{~T}$ and $(\mathrm{D}$ and $\mathrm{H}) 1.15 \mathrm{~T}$. (Red zones correspond to the regions analyzed by EDS probe) 
Table S4. Effect of magnetic field on the permeate flux: slope and $\mathrm{R}^{2}$ values for membrane with sphere-like and vesicle-like structured top layer at a transmembrane pressure of 1 and 2 bar.

\begin{tabular}{|c|c|c|c|c|}
\hline Membrane Type & $\begin{array}{c}\text { Transmembrane } \\
\text { pressure } \\
\text { (bar) }\end{array}$ & Magnetic field & Slope & $\mathrm{R}^{2}$ \\
\hline \multirow{4}{*}{$\begin{array}{l}\text { Sphere-like structured } \\
\text { top layer }\end{array}$} & \multirow[t]{2}{*}{1} & 0 to $0.4 \mathrm{~T}$ & 48.3 & 0.94 \\
\hline & & 0.4 to $1.15 \mathrm{~T}$ & 10.6 & 0.98 \\
\hline & \multirow[t]{2}{*}{2} & 0 to $0.4 \mathrm{~T}$ & 89.2 & 0.94 \\
\hline & & 0.4 to $1.15 \mathrm{~T}$ & 20.6 & 0.99 \\
\hline \multirow{4}{*}{$\begin{array}{l}\text { Vesicle-like structured } \\
\text { top layer }\end{array}$} & \multirow[t]{2}{*}{1} & 0 to $0.4 \mathrm{~T}$ & 36.0 & 0.97 \\
\hline & & 0.4 to $1.15 \mathrm{~T}$ & 7.3 & 0.99 \\
\hline & \multirow[t]{2}{*}{2} & 0 to $0.4 \mathrm{~T}$ & 73.5 & 0.97 \\
\hline & & 0.4 to $1.15 \mathrm{~T}$ & 14.5 & 0.99 \\
\hline
\end{tabular}
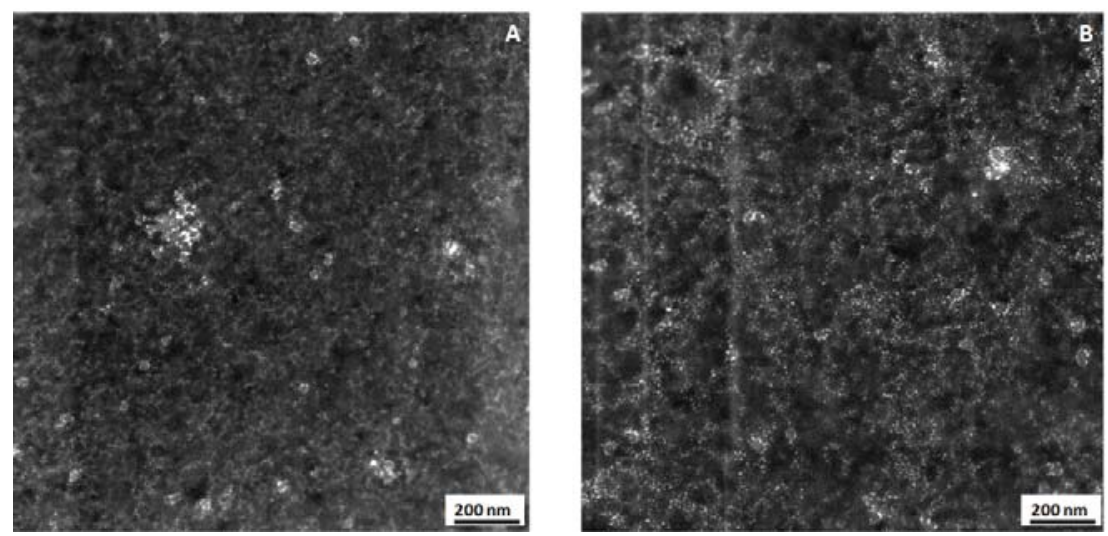

Fig. S6. STEM analysis of copolymer nanoparticle solution containing DMSA-coated iron oxide nanoparticles (A) no magnetic field (B) magnetic field at $0.4 \mathrm{~T}$. 